The Feasibility of Cask "Fingerprinting" as a Spent-Fuel, Dry-Storage Cask Safeguards Technique

K. P. Ziock, P. Vanier, L. Forman, G. Caffrey, J. Wharton, A. Lebrun

October 5, 2005 
This document was prepared as an account of work sponsored by an agency of the United States Government. Neither the United States Government nor the University of California nor any of their employees, makes any warranty, express or implied, or assumes any legal liability or responsibility for the accuracy, completeness, or usefulness of any information, apparatus, product, or process disclosed, or represents that its use would not infringe privately owned rights. Reference herein to any specific commercial product, process, or service by trade name, trademark, manufacturer, or otherwise, does not necessarily constitute or imply its endorsement, recommendation, or favoring by the United States Government or the University of California. The views and opinions of authors expressed herein do not necessarily state or reflect those of the United States Government or the University of California, and shall not be used for advertising or product endorsement purposes.

This work was performed under the auspices of the U.S. Department of Energy by University of California, Lawrence Livermore National Laboratory under Contract W-7405-Eng-48. 


\title{
The Feasibility of Cask "Fingerprinting" as a Spent-Fuel, Dry-Storage Cask Safeguards Technique
}

\author{
Klaus Ziock \\ Lawrence Livermore National Laboratory \\ Peter Vanier and Leon Forman \\ Brookhaven National Laboratory \\ Gus Caffrey, Jason Wharton \\ Idaho National Laboratory \\ Alain Lebrun \\ International Atomic Energy Agency
}

\begin{abstract}
This report documents a week-long measurement campaign conducted on six, dry-storage, spentnuclear-fuel storage casks at the Idaho National Laboratory. A gamma-ray imager, a thermalneutron imager and a germanium spectrometer were used to collect data on the casks. The campaign was conducted to examine the feasibility of using the cask radiation signatures as unique identifiers for individual casks as part of a safeguards regime. The results clearly show different morphologies for the various cask types although the signatures are deemed insufficient to uniquely identify individual casks of the same type. Based on results with the germanium spectrometer and differences between thermal neutron images and neutron-dose meters, this result is thought to be due to the limitations of the extant imagers used, rather than of the basic concept. Results indicate that measurements with improved imagers could contain significantly more information. Follow-on measurements with new imagers either currently available as laboratory prototypes or under development are recommended.
\end{abstract}




\section{Table of Contents}

1. Introduction

2. Introduction to coded aperture imaging

3. Instrumentation $\ldots$

a. Gamma-ray imager

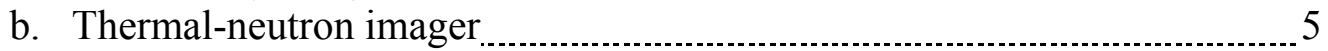

c. Gamma Spectrometer

4. Tan Facility

5. Measurements

a. Cask 1: Westinghouse MC-10 _.............................................. 8

i. Gamma-Ray Images $\ldots$

ii. Germanium Spectrometer Data $\ldots \ldots$

iii. Neutron Images $\ldots$

b. Cask 2: NuPac 125B

i. Gamma-Ray Images $\ldots \ldots \ldots$

ii. Germanium Spectrometer Data $\ldots \ldots \ldots$

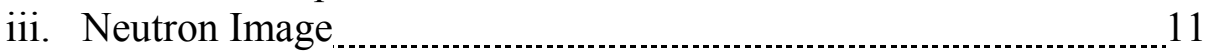

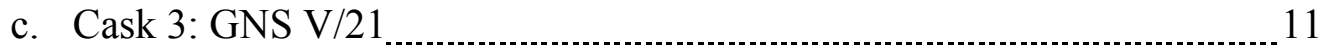

i. Gamma-Ray Images _...................................................... 11

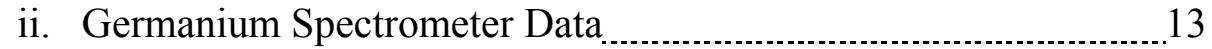

iii. Neutron Image

d. Cask 4: REA-2023

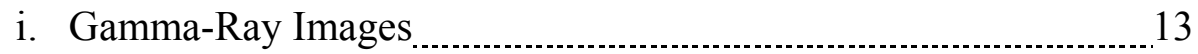

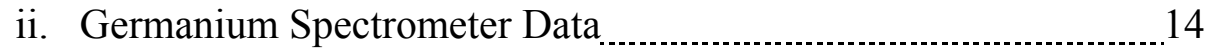

iii. Neutron Image

e. Cask 5: VSC-17

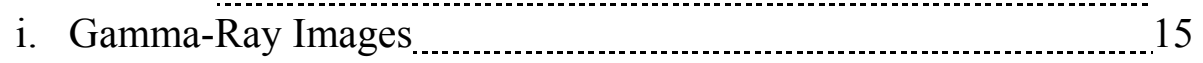

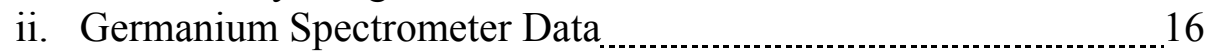

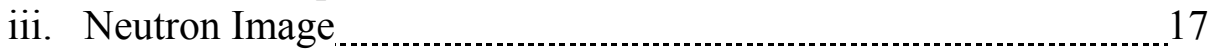

f. Cask 6: TN-24P

i. Gamma-Ray Images $\ldots \ldots \ldots \ldots$

ii. Germanium Spectrometer Data $\ldots \ldots \ldots$

iii. Neutron Image

6. Discussion

a. Gamma-Ray Results

b. Ideal Gamma-Ray Imager $\ldots$

c. Neutron Results

7. Conclusions

8. Recommendations

9. Acknowledgements $\ldots \ldots \ldots \ldots$

10. References 
Figure 2: Schematic coded-aperture imager $\quad 2$

Figure 3: Gamma-ray imager $\ldots$

Figure 4: Sample gamma-ray image

Figure 5: Zero-threshold gamma-ray image $\ldots$

Figure 6: Thermal-neutron imager

Figure 7: Polyethylene block neutron source photograph

Figure 8: Polyethylene block neutron source neutron image $\quad 6$

Figure 9: Polyethylene block neutron source simulation 6

Figure 10: Germanium spectrometer

Figure 11: TAN cask layout $\quad 7$

Figure 12: Cask 1 wide-angle gamma-ray image $\ldots \ldots$

Figure 13: Cask 1 zoomed gamma-ray image $\ldots$

Figure 14: Cask 1 second wide-angle gamma-ray image _............................... 11

Figure 15: Cask 1 overhead gamma-ray image 11

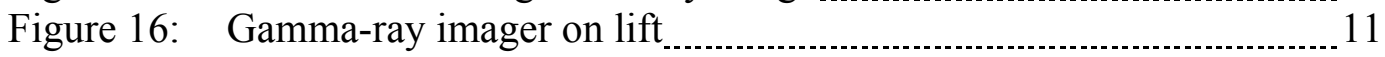

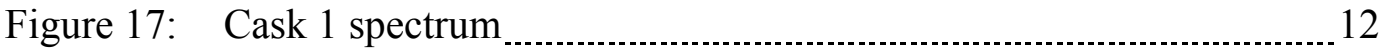

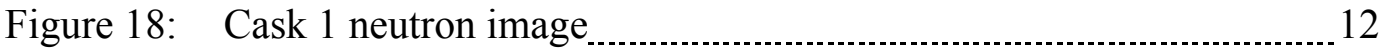

Figure 19: Cask 1 histogram of neutron image $\quad 12$

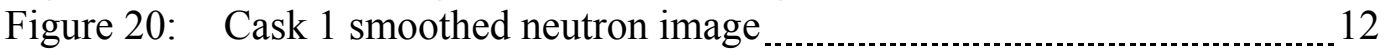

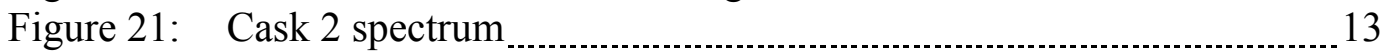

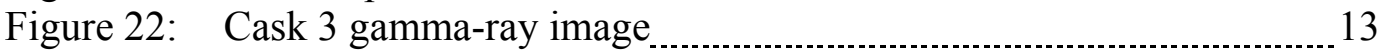

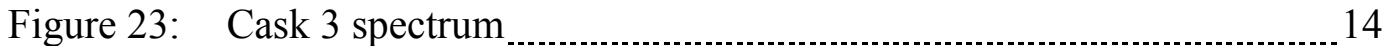

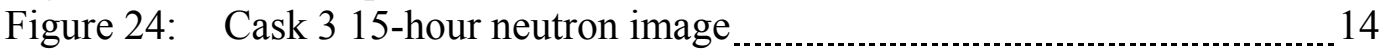

Figure 25: Cask 3 neutron image with 1 hour of anti-mask data

Figure 26: Cask 4 gamma-ray image

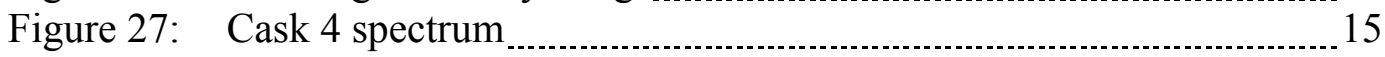

Figure 28: Cask 4 neutron image $\quad 15$

Figure 29: Cask 4 histogram across neutron image $\quad 15$

Figure 30: Cask 5 wide-angle gamma-ray image $\ldots \ldots$

Figure 31: Cask 5 zoomed gamma-ray image $\ldots$

Figure 32: Cask 5 spectrum $\ldots$

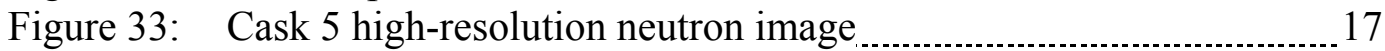

Figure 34: Cask 5 smoothed high-resolution neutron image 17

Figure 35: Cask 5 low-resolution neutron image $\quad 17$

Figure 36: Cask 6 spectrum $\ldots \ldots \ldots \ldots$

Figure 37: Cask 6 neutron image

Figure 37: Wide angle gamma-images with histograms .................................... 19

Table 1: $\quad$ Cask load summaries

Table 2: $\quad$ Cask image cross-reference

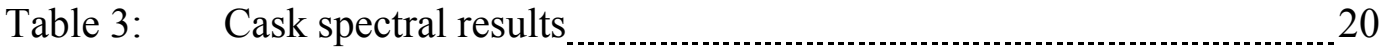




\section{Introduction}

Accounting for spent nuclear fuel is one of the important safeguarding tasks performed by the IAEA. The material is both highly radioactive and can contain significant quantities of fissile material. For the ten years following the last burn cycle, the material is generally stored in wet-storage facilities or "ponds" at the reactor site. After this time, it can be transferred to dry storage casks and moved to pads awaiting final disposal. Despite the fact that we are over five decades into the nuclear era, no long-term disposal sites exist. This means that more and more material is accumulating at "temporary" storage facilities in dry storage casks.

Although there are many types of dry storage casks, they all share the basic design goal to limit radiation exposure outside the cask. This means that cask walls include significant shielding for both neutron and gamma-radiation. Hence, traditional non-destructive analysis (NDA) and assay techniques to verify cask contents are ineffective after a cask is sealed. The safeguard regime therefore relies on the use of tags and seals $(\mathrm{C} / \mathrm{S})$ with regular inspections to maintain continuity of knowledge that cask contents remain as loaded.

The casks are loaded in the presence of IAEA inspectors by the reactor operators and "irreversibly" sealed. Tamperproof tags and seals $(\mathrm{C} / \mathrm{S})$ are added by the inspectors. The casks are then moved to a storage "farm" where many casks are stored. Periodic inspection of the tags and seals is currently the only technique that exists to certify that the cask contents have not been altered. As the inventory of spent fuel increases around the world, monitoring of cask loading operations and subsequent tags and seals inspections are creating a greater burden on IAEA resources.

The ever-increasing quantity of casks requiring regular inspection increases the likelihood that tags and seals will fail. This is particularly problematic since the casks are generally stored out of doors, exposed to the weather. In the event of $\mathrm{C} / \mathrm{S}$ failure, there is currently no means of reestablishing a cask's contents without reopening it. This technique is not considered realistic in light of the costs associated with such an undertaking.

In the late winter of 2003, the IAEA held a workinggroup meeting of experts to examine the means of safeguarding spent nuclear fuel. The panel focused on both wet and dry storage facilities. One of the suggestions made in the subsequent report [1] was to examine the idea of "fingerprinting" as a means to re-certify the contents of a cask in the event of $\mathrm{C} / \mathrm{S}$ failure and also as a means of strengthening the $\mathrm{C} / \mathrm{S}$ regime itself. The general concept relies on identifying cask properties that can be used to uniquely establish a cask ID and that the contents of that cask have not been significantly altered.

At the heart of the technique are the facts that the casks are loaded with fuel assemblies of varying burn-up and that radiation from the fuel reaches the cask surface despite the heavy shielding used in cask construction. The amount and type of radiation emitted by the fuel assemblies is known to be a function of their burn-up. In the loading process, the more heavily-used fuel elements are distributed throughout the cask to distribute the heat load within the cask. In principle, this should result in a multi-lobe signature of the radiation field.

It is expected that some vestige of the radiation pattern will survive to the cask surface The pattern will have two components. The first and major constituent will be due to radiation that interacts in the cask walls on the way to the surface. This radiation will generate a diffuse image, such as that obtained from a light bulb behind a glass diffuser. The second, smaller, component of the radiation field will exit the cask without interacting with the cask at all. This radiation will provide a faithful rendition of the geometry of the outer nuclear materials. (The inner fuel elements will be shielded by the outer layers and will be difficult to image directly.)

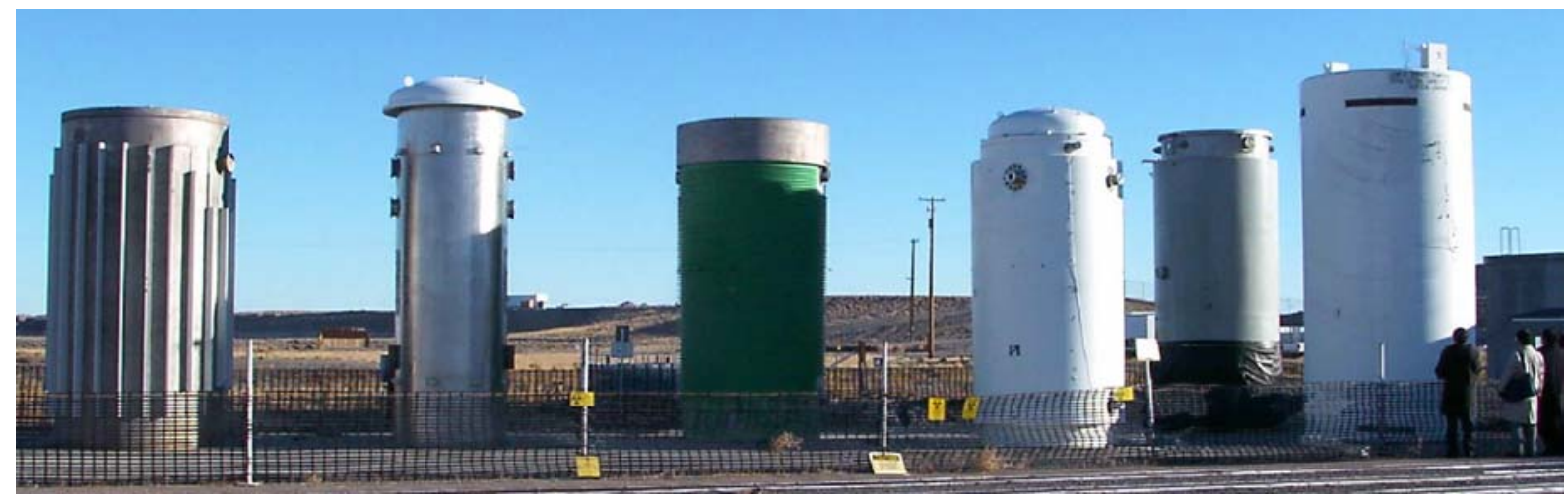

Fig. 1 Six casks at TAN facility INL. 

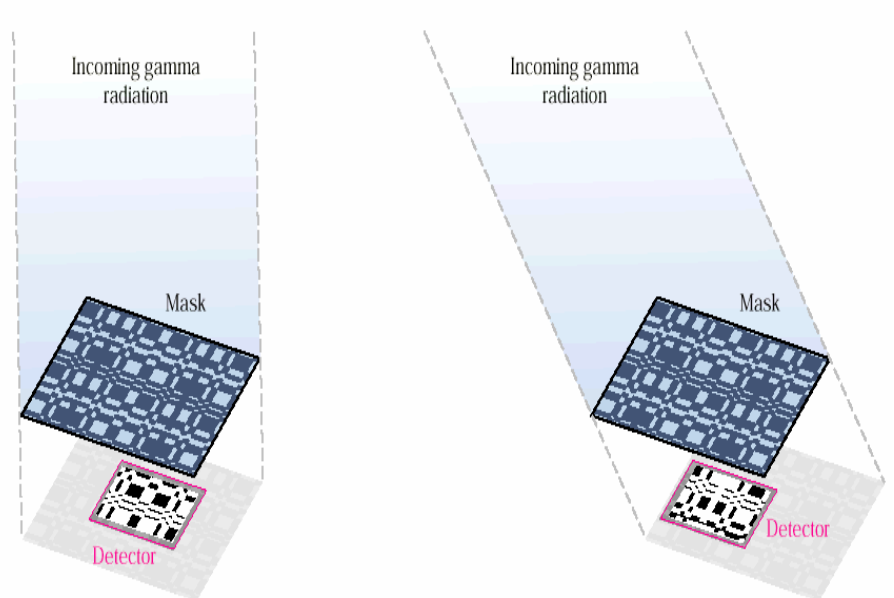

Fig. 2. Schematic representation of a coded aperture imager. Plane-parallel radiation coming from different directions, projects different parts of the mask pattern onto the detector. The detector sized portions of the mask are unique and do not interfere with each other.

It is thought that the overall radiation pattern can be used as an important constituent of the cask "fingerprint." Further it was suggested that this radiation field could be measured with the use of radiation imaging instruments.

Based on these recommendations, a measurement campaign including both a thermal neutron[1] and gammaray imager[2] was undertaken at Idaho National Laboratory (INL.) At the Test Area North (TAN) site of INL, there are six different spent fuel casks (see Fig. 1.) This report documents the results obtained during this campaign and makes recommendations for future work on this concept.

\section{Introduction to coded aperture imaging}

The penetrating nature of the gamma-rays and neutrons that allows them to be detected outside of a cask also makes constructing an imager for these types of radiation difficult. In addition to a source of radiation, to generate an image generally requires a positionsensitive detector and a focusing optic. The former can be difficult to fabricate, the latter, save for a pin-hole camera, is impossible with current technologies.

The problem with a pin-hole camera is that it makes an image by rejecting all but a small fraction of the radiation incident on an instrument. Fortunately, the efficiency of the pin-hole camera can be increased by piercing the blocking surface with more than one hole. This has the advantage that more radiation reaches the detector, decreasing the imaging time. It has the disadvantage that each hole generates its own image and these images will overlap for all but the simplest scenes. In the limit, where a large fraction of the blocking sheet is pierced $(\sim 50 \%)$ it is best to think in terms of the shadow pattern that is created. Then, an ideal multiple pinhole camera must have two attributes: 1) a unique shadow pattern must be cast onto the detector by a point source in each pixel of the field-of-view and 2) the shadow patterns for different pixels in the field of view must not interfere with each other, i.e. they must be "orthogonal." Such patterns were perfected in the 1970's by the high energy astrophysical community and are called coded apertures. They are described in more detail in [3-5].

A schematic representation of a coded aperture imager is given in Fig. 2. The shadow mask is placed a focal length $(f)$ in front of a position-sensitive detector. The mask must be largely opaque to the radiation to be imaged and has four times the area of the detector. It is made of a four-fold replication of a base pattern called a uniformly redundant array (URA). A source in a given pixel of the field of view will project one of the detector-sized patterns on to the detector. Each such pattern is unique, allowing one to determine where a source is located. The patterns are also orthogonal in the sense that the URA pattern autocorrelates to a delta function. Hence a faithful image can be generated mathematically from the pattern encoded at the detector.

For a base pattern $\mathrm{r} x \mathrm{~s}$ in size, (mask $2 \mathrm{r} \times \mathrm{x}$ ) ) there will be $\mathrm{r}$ x s unique detector-sized patterns giving a field of view of $\mathrm{r}$ x s pixels. Generally, it is desirable to over sample the mask pattern by at least a factor of 2 (i.e. the detector pixels are one quarter the area of a mask pixel.)[5] The angular resolution of the imager is the size of the base mask element, $a$, divided by the focal length, $f$. To obtain a position resolution at the source one multiplies the angular resolution by the distance to the source, $d$, hence:

$$
\Delta \mathrm{X}=\frac{a}{f} d
$$

Of concern in coded aperture imaging is that the image is encoded as a variation in counts as a function of position across the detector face. Anything that produces such a variation leads to structures in the image. If the variations are not from the shadow of the mask pattern, the structures in the image will be artifacts and not representative of the radiation field in the field of view. Fortunately, a simple technique exists to measure such modulations without compromising accumulation time. $[5,6]$ 


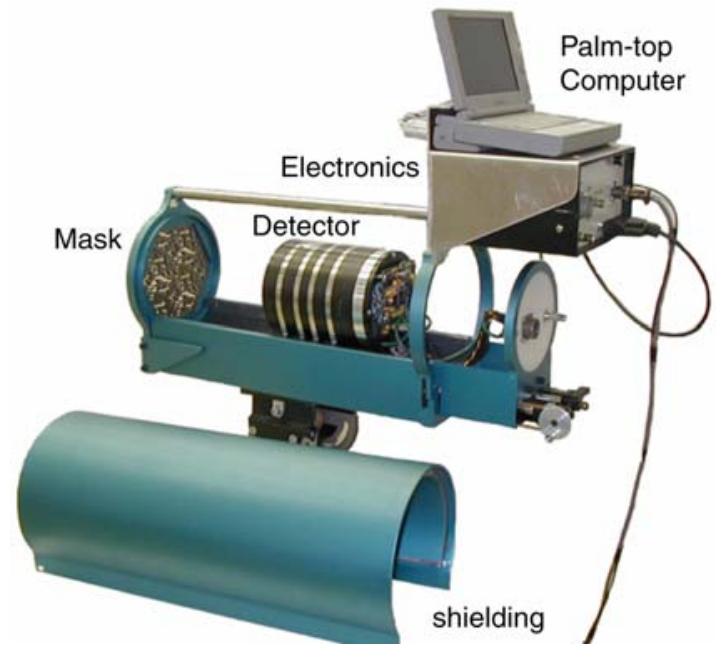

Fig. 3. Current-generation imager. The unit is battery powered and provides variable zoom images.

Some families of the coded apertures (hexagonally uniformly redundant arrays, HURA [7] and modified uniformly redundant arrays, MURA [8]) are anti- symmetric when rotated about their central pixels by a fixed amount (60 and 90 degrees for the HURA and MURA, respectively). With knowledge of this property, the image can be taken in two sessions, one with the "mask" orientation of the shadow mask and one with its inverse or "anti-mask" orientation. When added together, the resulting data set has no modulation from the mask pattern. Therefore, any modulation must be spurious and can be removed before the mask and antimask data are deconvolved separately and added together to form the final image. This procedure makes the coded-aperture technique very robust, providing faithful images in high background environments.

There is a penalty inherent to coded aperture imaging when compared to direct imaging techniques. To unfold the image requires using all of the data in the detector to generate each pixel of the image. This means that the standard deviation of the statistical noise in each pixel is the square-root of the total number of counts in the detector as a whole. This is higher than in a "trueimager" where the radiation from one direction over the entire instrument aperture is concentrated onto the detector with the use of a lens or other imaging optic. In
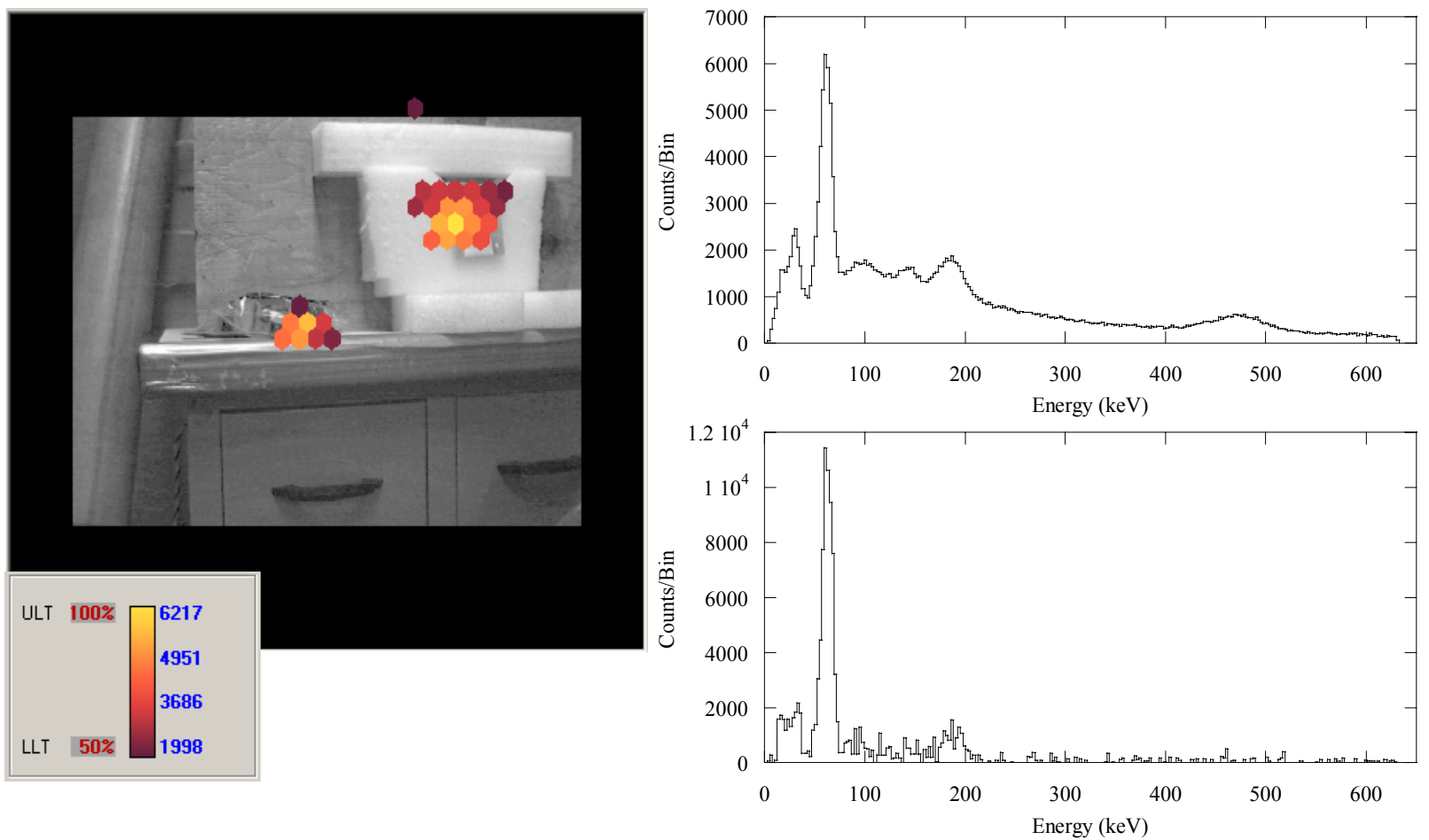

Fig. 4. The standard gamma-ray imager data as it is presented in the report. The image is of two point sources taken with the gamma-ray imager after it was unpacked at INL. The two sources are HEU (left) and ${ }^{241}$ Am (right.) The gamma-ray image is scaled to the video image and pixels below 50\% peak intensity are turned clear so that the visible-light image can be seen for reference. This data was taken with the widest gamma-ray field of view. In such data, the field of view of the visible light image is less than that of the gamma-ray image; hence the black border about the visible light image. The top spectrum is from all of the events collected by the imager. The lower spectrum is just for the gamma-ray pixels that are colored (above the 50\% threshold.) As seen, the latter spectrum can differ significantly from the total spectrum. This is further exemplified in Fig. 5. 
that case the standard deviation in each pixel of the image is the square-root of the counts in just that pixel of the detector. As a consequence, the advantage of a coded-aperture imager over a pin-hole camera is best for a point source, when only a single pixel in the field of view is bright. In this situation, the advantage in signal-to-noise ratio over the pin-hole is given by the square root of the number of open pixels in the base pattern. As more of the field of view glows from extended sources, the advantage decreases until, in the limit where the whole field of view glows, the sensitivity reverts to approximately that of the pin-hole camera.[4]

An additional property of coded aperture imagers that one must consider in this application is the confusing effect of partially encoded sources. Because the mask pattern is a replication of the base pattern, a source that falls outside the primary field of view will be imaged at the wrong location. Specifically, it will appear on the opposite side with some additional noise spread throughout the image. Although this problem can be successfully removed through the inclusion of suitable detector collimation, neither of the imagers described below makes us of this technique.

\section{Instrumentation}

The cask measurements reported below were conducted using a thermal neutron and a gamma-ray imager. Both of these instruments form images using the codedaperture technique described above. However, they differ significantly in the position-sensitive detectors, mask and shielding materials required by their respective radiation types. The specifics of each instrument are described in more detail below. In addition to the imagers, a collimated coaxial germanium detector was used to determine the gamma-ray spectrum from each of the casks. The details of this system are also provided below.

\section{Gamma-Ray Imager}

The gamma-ray imager used in these measurements is shown in Fig. 3 and is described in detail in Ziock and Nakae.[2] It comprises a base-19, HURA, codedaperture mask used to project a shadow pattern onto a CsI(Na)-based, position-sensitive, gamma-ray detector. The mask is $5 \mathrm{~mm}$ thick Ta with a hexagonal hole size of $2.14 \mathrm{~mm}$ per flat face. The detector uses a $12-\mathrm{cm}$ diameter, one-centimeter thick $\operatorname{CsI}(\mathrm{Na})$ disk to convert incident gamma-rays to a flash of scintillation light. The CsI is mounted on a Hamamatsu R3292 [9] position-sensitive-photomultiplier tube (PSPMT). The location and energy of each gamma-ray event is determined by measuring and centroiding the scintillation light flash as described in [2]. The position resolution of the detector is $\sim 3 \mathrm{~mm}$ and the energy resolution is $\sim 11 \%$ at $356 \mathrm{keV}$. The detector is mounted on linear bearings that allow it to be moved and set in one of five different
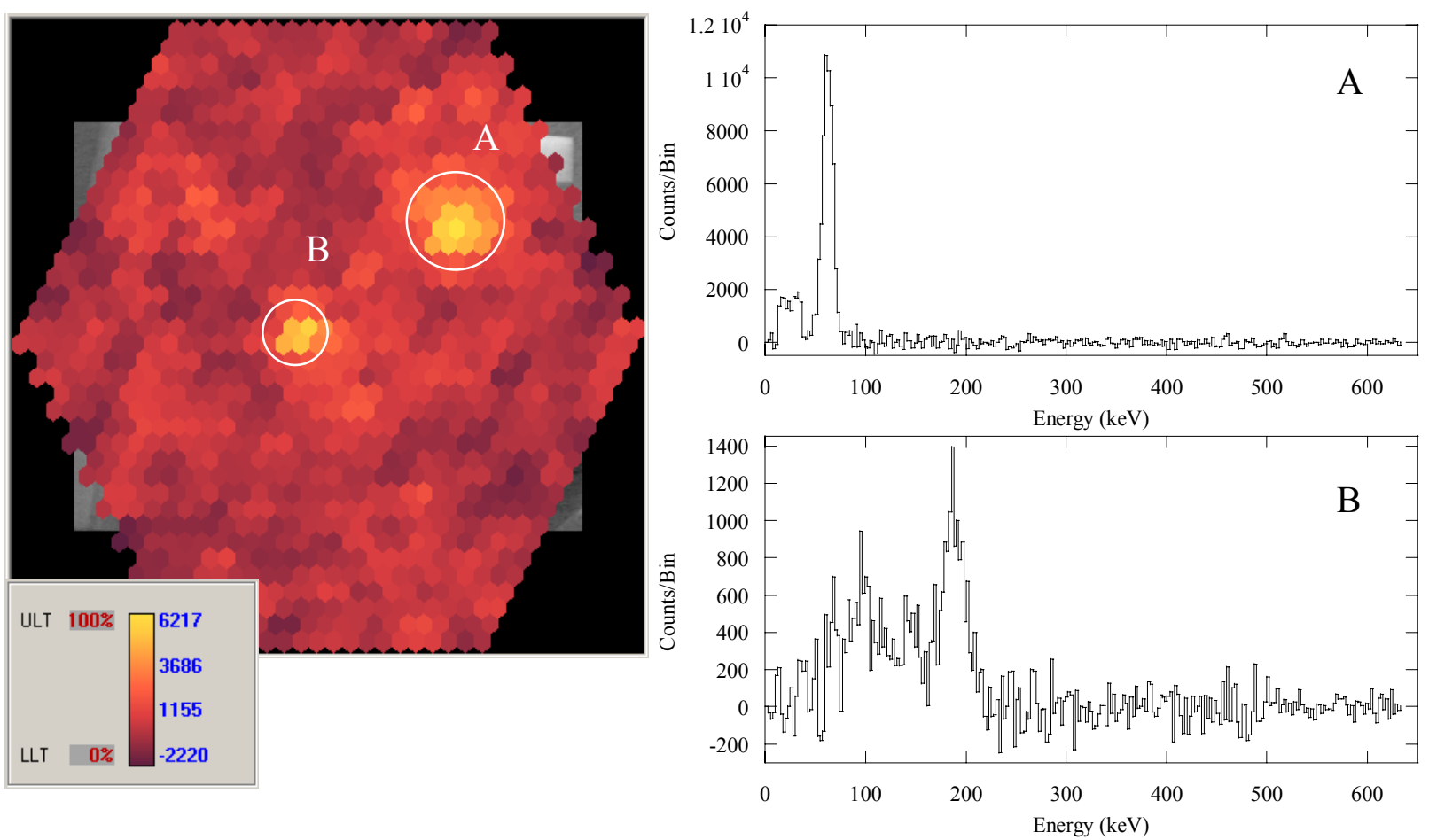

Fig. 5. Same data as Fig. 4, but with the gamma-ray image threshold set to zero. The hexagonal field of view of the imager is readily apparent. The spectra on the right are from the yellow pixels within each of the circles. This clearly identifies the Am source as source A and source B as the HEU. 


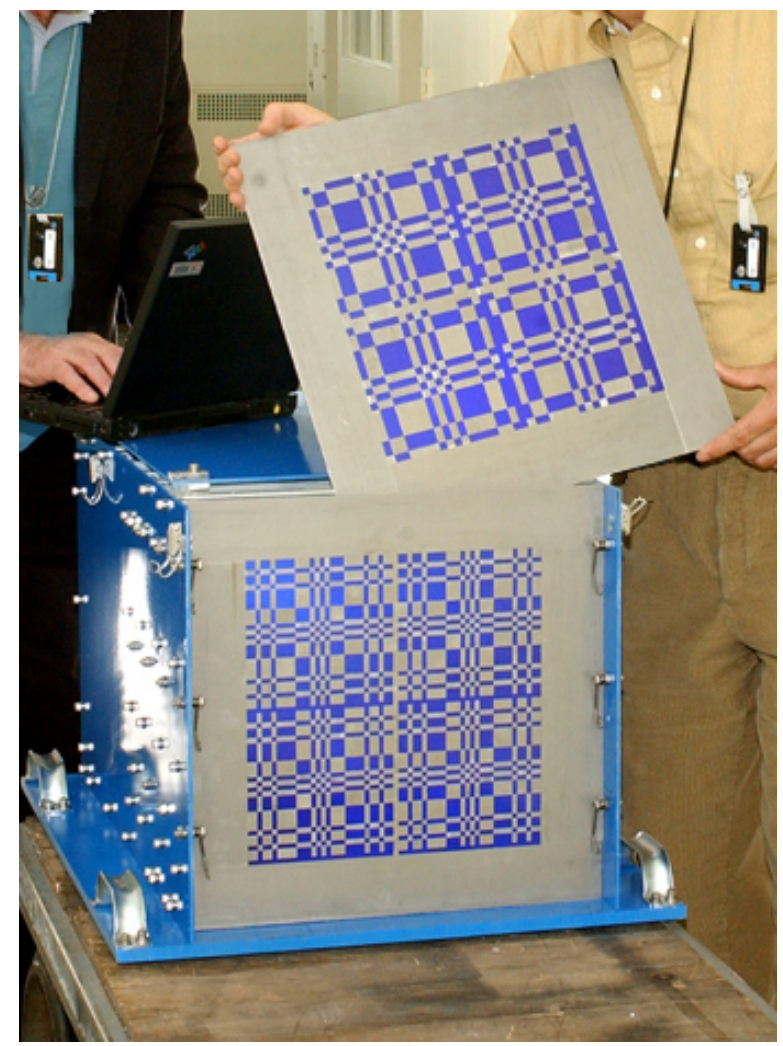

Fig. 6. Code-aperture, thermal-neutron imager.

focal lengths from the mask, providing a zoom capability. Data from the PSPMT is collected by a gatedintegrator-based data acquisition system that uses a commercial, 16-bit digitizer mounted in a palm-top computer. The computer records the data in list-mode and also generates an online image that is periodically updated.

As discussed above, the data is collected in two, equaltime integrations, one in the "mask" and one in the "anti-mask" orientation. A 60-degree rotation of the mask must be performed between the two integrations.

In addition to the gamma-ray data, a visible-light video camera, coaligned with the imaging axis of the instrument, is used to record a visible-light image before each run. Based on the measured distance to the source, the visible-light image is scaled to the gamma-ray image and the two are simultaneously displayed in an overlay mode on the computer screen. The gamma-ray image is shown in false-color "in front" of the visible-light image. Those gamma-ray pixels a selectable-value below the maximum are turned clear so that portions of the visible-light image can be seen (Fig. 4). Up to four energy regions-of-interest may be set before a run. Separate images are made in each of these energy bands and in the overall spectrum during the run.
The list-mode data file recorded during an acquisition includes all of the information available about each gamma-ray event. Hence, a complete post-acquisition analysis can be performed with these data files allowing the user to vary software settings (such as source distance and energy cuts) as if these changes were made during the actual acquisition. In addition to the on-line displays that are generated as data is accumulated (or replayed,) a separate detector record is maintained for each energy bin of the imager. Upon completion of an acquisition, these can be individually deconvolved to create a separate image for each energy bin. The resulting data-cube is used to interactively determine both the images obtained with different energy cuts on the data, and the spectrum from different pixels or regions of the image (Fig. 5.) [10]

Finally, it should be noted that the gamma-ray imager used in these measurements is a prototype instrument developed for use in arms-control applications. As such, it is optimized to respond to gamma-radiation from highly-enriched uranium (HEU) at $186 \mathrm{keV}$ and the 374 and $414 \mathrm{keV}$ lines from plutonium. In addition, it provides excellent response at the $\sim 100 \mathrm{keV} \mathrm{K}$-shell fluorescence radiation from these elements. Unfortunately, the upper limit of the electronics is set to 630 $\mathrm{keV}$, a value that is too low to image any of the line radiation that was measured to leak from the casks with the Ge spectrometer.

\section{Thermal-Neutron Imager}

The thermal neutron imager is based on a crossed-wire chamber with a $20-\mathrm{cm} \times 17-\mathrm{cm}$ sensitive area operated in the proportional mode with a gas mixture of 6 bar of ${ }^{3} \mathrm{He}$ and 2.5 bar of propane. Details of the construction and the readout electronics can be found elsewhere [11]. The detector chamber is enclosed in a cadmiumlined box equipped with one of three choices of codedaperture, MURA masks fabricated from 0.4-mm thick cadmium pixels mounted on an unperforated aluminum backing sheet. A mask can be inserted in one of four different tracks at different focal lengths, and can be used as its own anti-mask by rotating through a right angle about the optic axis before insertion into the track. The base pattern of each mask is a square of 15 $\mathrm{cm} \times 15 \mathrm{~cm}$, and the three masks available consist of (A) $19 \times 19$ (B) $31 \times 31$ and (C) $47 \times 47$ pixels in the base pattern, with four copies tiled to make each a complete mask. For most of the data in this report, the focal length is $10 \mathrm{~cm}$, and the width of the field of view at the source is therefore 1.5 times the distance to the cask. The imager is shown in Fig. 6.

A custom-built, data-acquisition board is used to accumulate a 2-dimensional spatial histogram of neutron absorption events. The histogram consists of a $608 \mathrm{x}$ 


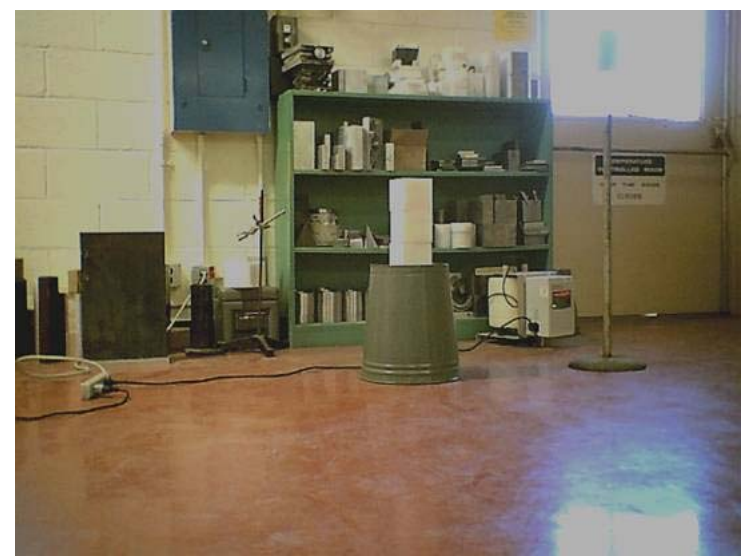

Fig. 7. Test of neutron imager in the laboratory using three PE cubes with ${ }^{252} \mathrm{Cf}$ sources embedded in the top and bottom cubes

512 array of 32-bit integers that can be zeroed or read out at any time by the controlling laptop computer through a 32-channel, digital, PCMCIA interface.

The spatial resolution of the chamber is limited to about $1 \mathrm{~mm}$ by the difference in ranges of the proton and triton produced by the reaction of a neutron with ${ }^{3} \mathrm{He}$, because the recoil direction is not determined. Nevertheless, the readout electronics oversamples the resolution elements by about a factor of 3 in both $\mathrm{x}$ and $\mathrm{y}$. The smallest mask pixel ( $3 \mathrm{~mm} \times 3 \mathrm{~mm}$ ) is consequently oversampled by about a factor of 9 in each direction. (The detector has far better resolution than is needed for this application because it was originally designed for a different purpose - protein crystallography with cold neutron beams.) This oversampling provides a high

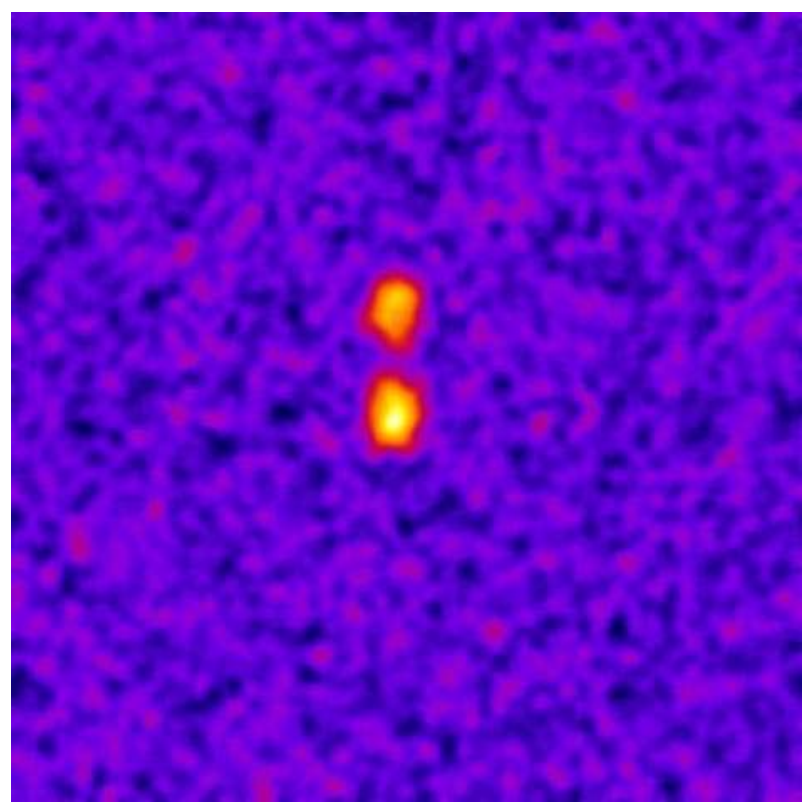

Fig. 8. Thermal neutron image of configuration in Fig 7 , acquired in 10 minutes using the $47 \times 47$ MURA mask

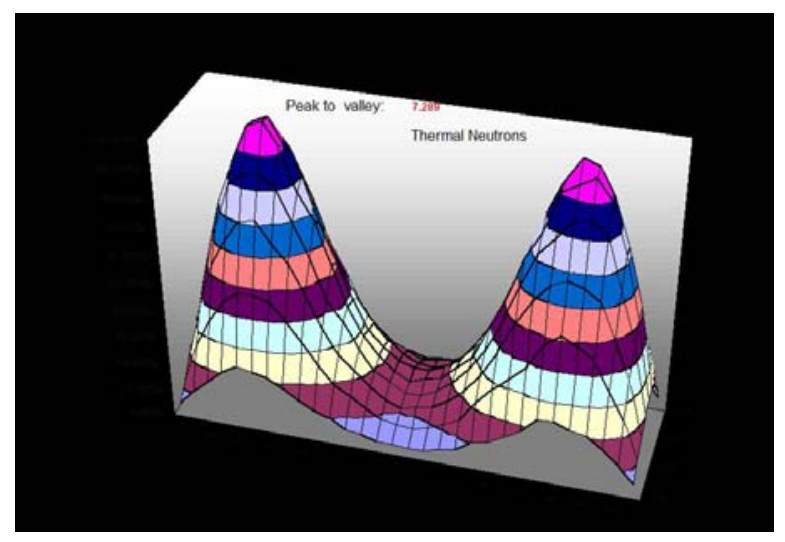

Fig. 9. Monte Carlo simulation of thermal neutron leakage from three cubes containing two sources

degree of adjustability in the image-processing software, which allocates regions of the detector to pixels of the mask shadow while taking account of the magnification of the shadow at short ranges. Optimizing the focus for objects in the scene at different ranges can therefore be performed by software after the data are recorded. Also, physical registration of detector elements with mask pixels is not required.

Laboratory tests of the imager at INL before deployment at the TAN facility demonstrated the resolution and contrast that can be achieved with ideal thermal neutron sources. Two ${ }^{252} \mathrm{Cf}$ spontaneous fission sources were embedded at the centers of cubes of high density polyethylene (PE) of dimensions $10 \mathrm{~cm}$ on the side. These moderating cubes were stacked with another cube between them, as shown in Fig. 7.

The resulting neutron image, shown in Fig. 8, was obtained using the C-mask at a range of $3 \mathrm{~m}$ with a focal length of $30 \mathrm{~cm}$. The image is consistent with a range of $\sim 5 \mathrm{~cm}$ for $2 \mathrm{MeV}$ neutrons in PE. Thermal neutrons leak preferentially from the centers of the faces of the cubes holding the sources, and do not fill the three cubes uniformly.

The configuration was modeled by Alain Lebrun using a Monte Carlo code (see Fig. 9.) The lack of thermal neutrons emitted from the face of the center cube is a consequence of the fact that the thermalization distance of the fission neutrons is somewhat less than $5 \mathrm{~cm}$ in $\mathrm{PE}$, and the diffusion length for thermal neutrons is considerably less than $5 \mathrm{~cm}$. Therefore, the maximum intensity is seen at the center of the face of each cube that contains a source.

\section{Gamma spectrometer}

The high-resolution gamma-ray spectra recorded for the casks were taken using a 39\% relative-efficiency, N- 


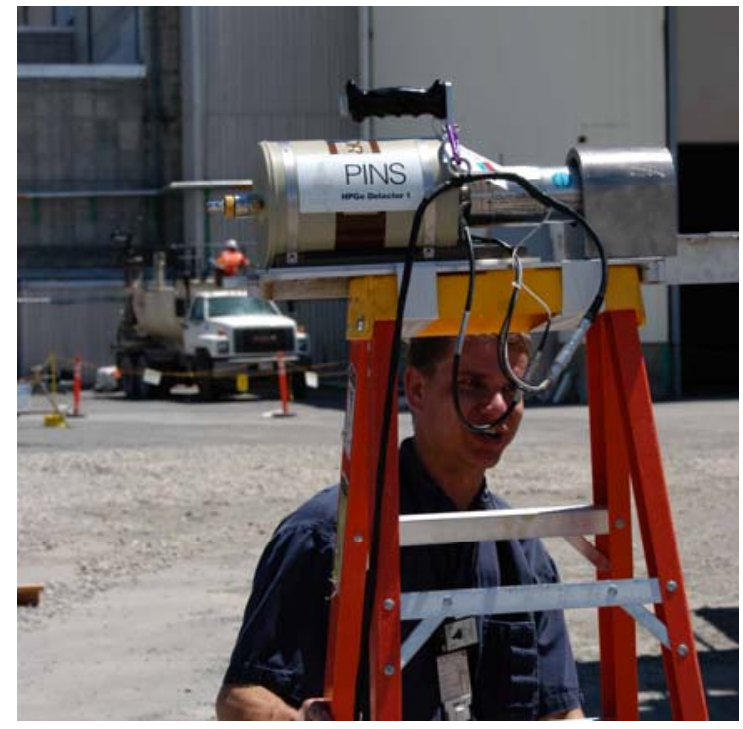

Fig. 10. The Ge spectrometer and collimator.

type, coaxial, high-purity, germanium detector. It is collimated with a bismuth annulus restricting its field of view to 10 degrees. The system is the same as used for PINS work and has been described in detail elsewhere [12]. The data were collected using an ORTEC NomadPlus, portable, multi-channel analyzer. The deadtime of the measurements was kept below 26\%. Data were collected from a distance of $3 \mathrm{~m}$ and the detector was elevated $1.8 \mathrm{~m}$ above the ground, at approximately cask mid-height. The system is shown in situ in Fig. 10.

\section{TAN facility}

The "Test Area North" at Idaho National Laboratory (INL) has a facility to perform experimental measurements on six different, spent-nuclear-fuel, dry-storage casks. These are set out doors on a concrete pad meas- uring 28.6 x $12.9 \mathrm{~m}$ (Fig. 1 and 11). A fence surrounding the edge of the pad provides a personnel boundary between the general and a radiation zone. Flux at the boundary can be as high as $5 \mathrm{mR} / \mathrm{hr}$. At a neighboring location, fuel and components from the Three Mile Island reactor are stored.

The following casks are located on the concrete pad. Details of loading are obtained from [13]:

1) Westinghouse MC-10. This cask contains 5 intact Turkey Point PWR assemblies, 12 VEPCO PWR assemblies and one BCD B-17 PWR assembly. The latter has 21 fuel rods replaced by stainless steel rods for a total of 183 fuel rods. Thus 18 of 24 possible locations are used for a total of 14.99 Metric Tons of Heavy Metal (MTHM).

2) NuPac 2125-B Cask. This cask contains Three Mile Island Reactor 2 debris canisters in two of 7 locations. The cask contains a total of 0.02 MTHM.

3) GNS Castor V/21 Cask. This Cask contains 21 VEPCO PWR assemblies. Twenty of the assemblies are intact while one has 12 rods removed for a total of 9.27 MTHM. The fuel was discharged from the Surry reactor in November 1981 and was in water storage until $7 / 85$ when it was loaded into the cask.[14] On average it has a burn-up of 30-35 GWd/MTU.[15]

4) REA-2023. This cask is loaded with commercial spent nuclear fuel comprising intact assemblies from Connecticut Yankee (PWR,) H. B. Robinson (PWR,) Beach Bottom (BWR) and Dresden I (BWR) reactors. Five positions in the cask are occupied by "loose" fuel rods.
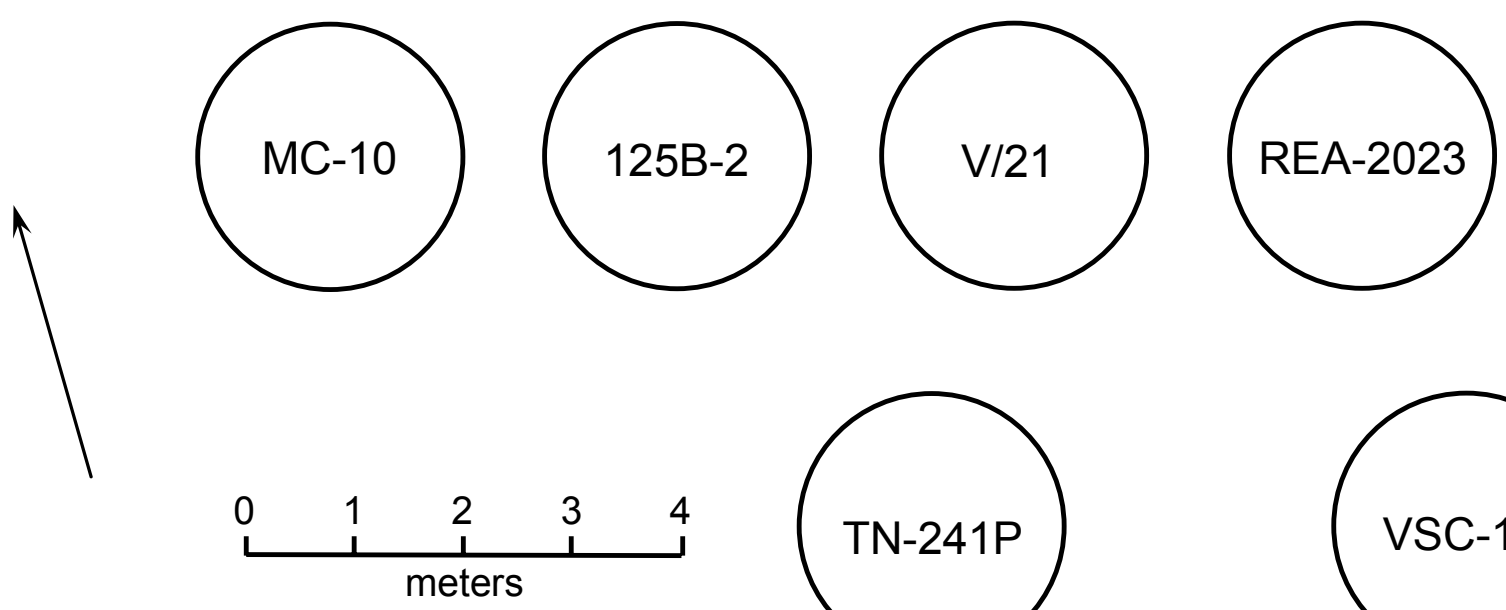

Fig. 11. Layout of the casks at the TAN facility. 
The cask also contains fuel from the Loss of Fluid Test (LOFT) reactor including the center module FP-1 with two rods removed and the remains of the FP-2 center module housed in ten storage cans that also contain two loose FP-rods and epoxy. The total Cask contents is 1.79 MTHW

5) Pacific Sierra Nuclear VSC-17 Cask. This cask contains fuel from the Dry Rod Consolidation Technology project (DRCT.) The canisters are each loaded with the fuel from two fuel assemblies. These were extracted from standard Westinghouse 15 x 15 zircalloy clad fuel assemblies from VEPCO and Turkey Point reactors. The cask contains a total of 5.31 MTHM.

6) Transnuclear TN-24P Cask. This cask contains seven DRCT canisters each with the fuel of two normal assemblies (see cask 5 above.) It also contains 12 LOFT assemblies for a total of 8.04 MTHM.

The contents of the various casks is summarized in Table 1 .

\section{Measurements}

The details of measurements and results for each cask are presented below. The gamma-ray image for each viewing angle and zoom is presented together with the associated energy spectrum. The threshold on the gamma-ray image is set at $50 \%$ for all but cask 3 where $60 \%$ was used due to the high noise level of the image. A summary of the images is given in Table 2.

\section{Cask 1: Westinghouse MC-10}

Gamma-ray images

This cask is the first one measured with the gamma-ray imager because the instrument could be positioned so that no other cask was in the imager's immediate field of view. To achieve this, the instrument was placed on the east side of the pad, close enough to the cask so that it hid the other casks. The cask's location did mean that radiation from the neighboring pad containing waste from the Three Mile Island reactors entered the back of the imager. This was noted as a reduction in the instantaneous count rate from $\sim 3100 \mathrm{c} / \mathrm{s}$ to $\sim 2600 \mathrm{c} / \mathrm{s}$ when the operator stood behind the instrument. To reduce this rate during the measurements, the battery pack from the instrument was placed immediately behind the imager head so that it's lead-acid cell blocked this radiation.

Four images of this cask were obtained. The first was a 20-minute, wide-angle integration from $8.65 \mathrm{~m}$ with a pixel size of $\sim 19.8 \mathrm{~cm}$ (Fig. 12.) Following this image, problems with the instrument required removing it for repair. For subsequent side-view measurements, the imager was moved closer to the cask. The second integration comprised a total of 180 minutes from $6.14 \mathrm{~m}$ with a pixel size of $\sim 8.5 \mathrm{~cm}$ (Fig. 13.) The third measurement was for a total of 120 minutes from the same distance but with a wider field of view resulting in pixels $14.1 \mathrm{~cm}$ across (Fig. 14.) Finally, a lift was used to obtain an oblique, top-down, view (Fig. 15.)

The overhead measurement provided several logistics challenges that might have affected the quality of the image. First, the imager had to be started with the lift retracted and then raised to the viewing position. This took varying times of order a few minutes. To change the mask to its anti-mask configuration, required lowering the imager, rotating the mask and re-raising the

Table 1

\begin{tabular}{|c|c|c|c|c|}
\hline \multicolumn{5}{|c|}{ Cask Load Summaries } \\
\hline Cask & Type & Origin & $\begin{array}{l}\text { Fuel } \\
\text { Units }\end{array}$ & МТHM \\
\hline \multirow{4}{*}{1} & \multirow{4}{*}{ MC-10 } & $\begin{array}{l}\text { Turkey } \\
\text { Point B-17 }\end{array}$ & 21 & 9.27 \\
\hline & & $\begin{array}{l}\text { Turkey } \\
\text { Point }\end{array}$ & 1 & 0.41 \\
\hline & & VEPCO & 12 & 5.31 \\
\hline & & & 34 & 14.99 \\
\hline 2 & $\begin{array}{l}\text { NuPac } \\
125 B\end{array}$ & $\begin{array}{l}\text { TMI Ep- } \\
\text { oxy }\end{array}$ & 2 & 0.02 \\
\hline 3 & $\begin{array}{l}\text { GNS } \\
\mathrm{V} / 21 \\
\end{array}$ & VEPCO & 21 & 9.27 \\
\hline \multirow{11}{*}{4} & \multirow{11}{*}{$\begin{array}{l}\text { REA- } \\
2023\end{array}$} & $\begin{array}{l}\text { LOFT FP- } \\
1\end{array}$ & 1 & 0.20 \\
\hline & & $\begin{array}{l}\text { LOFT FP- } \\
2\end{array}$ & 2 & 0.10 \\
\hline & & $\begin{array}{ll}\text { CT } & \text { Yan- } \\
\text { kee } & \\
\end{array}$ & 1 & 0.39 \\
\hline & & Dresden I & 1 & 0.11 \\
\hline & & Dresden I & 1 & 0.06 \\
\hline & & $\begin{array}{l}\text { H.B. Rob- } \\
\text { inson }\end{array}$ & 1 & .23 \\
\hline & & $\begin{array}{l}\text { Peach Bot- } \\
\text { tom }\end{array}$ & 2 & .28 \\
\hline & & LFRSB & 1 & 0.31 \\
\hline & & $\begin{array}{l}35 \text { encaps. } \\
\text { tubes }\end{array}$ & 3 & 0.09 \\
\hline & & Surry & 1 & 0.02 \\
\hline & & & 14 & 1.79 \\
\hline 5 & VSC-17 & DRCT & 17 & 5.31 \\
\hline \multirow{5}{*}{6} & \multirow{5}{*}{ TN-24P } & DRCT & 7 & 6.14 \\
\hline & & $\begin{array}{l}\text { LOFT } \\
\text { Center }\end{array}$ & 4 & 0.81 \\
\hline & & $\begin{array}{l}\text { LOFT } \\
\text { Corner }\end{array}$ & 4 & 0.28 \\
\hline & & LOFT Std & 4 & 0.81 \\
\hline & & & 19 & 8.04 \\
\hline
\end{tabular}


Table 2.

Cask Images

\begin{tabular}{|c|c|c|c|c|c|c|c|c|c|c|c|c|c|}
\hline \multicolumn{2}{|c|}{ Cask } & \multicolumn{6}{|c|}{ Gamma-Ray Images } & \multicolumn{6}{|c|}{ Neutron Images } \\
\hline Number & Type & View & $\begin{array}{c}\text { Res } \\
(\mathrm{cm})\end{array}$ & $\begin{array}{c}\text { Range } \\
\text { (m) }\end{array}$ & $\begin{array}{c}\text { Exposure } \\
\text { (min) }\end{array}$ & Counts/sec & Figs & View & $\begin{array}{c}\text { Res } \\
(\mathrm{cm})\end{array}$ & $\begin{array}{c}\text { Range } \\
(\mathrm{m})\end{array}$ & $\begin{array}{c}\text { Exposure } \\
\text { (min) }\end{array}$ & Counts & Figs \\
\hline \multirow{5}{*}{1} & \multirow{5}{*}{ MC-10 } & $\begin{array}{l}\text { Side } \\
\text { wide }\end{array}$ & $\begin{array}{l}18.3, \\
19.8 \\
\end{array}$ & 8.65 & 20 & 1178 & 10 & Side & 64 & 8.1 & 360 & $4.5 \times 10^{6}$ & 18,20 \\
\hline & & $\begin{array}{l}\text { Side } \\
\text { Wide }\end{array}$ & $\begin{array}{l}14.1, \\
13.1\end{array}$ & 6.14 & 180 & 1367 & 14 & & & & & & \\
\hline & & $\begin{array}{c}\text { Side } \\
\text { Zoom }\end{array}$ & $\begin{array}{l}13.1 \\
14.1 \\
\end{array}$ & 6.14 & 120 & 1325 & 13 & & & & & & \\
\hline & & Top & $7.0,6.5$ & 3.0 & 160 & 513 & 15 & & & & & & \\
\hline & & Spectrum & -- & 3 & 16.7 & -- & 17 & & & & & & \\
\hline 2 & $\begin{array}{c}\text { NuPac } \\
125 \mathrm{~B}\end{array}$ & Spectrum & -- & 3 & 16.7 & -- & 21 & None & & & & & \\
\hline \multirow{2}{*}{3} & \multirow{2}{*}{$\begin{array}{l}\text { GNS } \\
\text { V/21 }\end{array}$} & $\begin{array}{c}\text { Side } \\
\text { Wide }\end{array}$ & $\begin{array}{l}14.1, \\
13.1 \\
\end{array}$ & 6.15 & 60 & 396 & 22 & Side & 54 & 6.8 & $\begin{array}{l}900 \\
960 \\
\end{array}$ & $\begin{array}{c}10^{7} \\
1.06 \times 10^{7} \\
\end{array}$ & 24,2 \\
\hline & & Spectrum & -- & 3 & 16.6 & & 23 & & & & & & \\
\hline \multirow{2}{*}{4} & \multirow{2}{*}{$\begin{array}{l}\text { REA- } \\
2023\end{array}$} & $\begin{array}{c}\text { Side } \\
\text { Wide }\end{array}$ & $\begin{array}{l}13.8, \\
12.8 \\
\end{array}$ & & 60 & 962 & 26 & Side & 36 & 4.5 & 120 & $1.1 \times 10^{6}$ & 28 \\
\hline & & Spectrum & -- & 3 & 33.3 & -- & 27 & & & & & & \\
\hline \multirow{3}{*}{5} & \multirow{3}{*}{ VSC-17 } & $\begin{array}{c}\text { Side } \\
\text { Wide }\end{array}$ & $\begin{array}{l}17.8, \\
19.2 \\
\end{array}$ & 8.38 & 60 & 702 & 30 & $\begin{array}{c}\text { Side } \\
\text { Hi-res } \\
\end{array}$ & 19 & 5.8 & 60 & $0.8 \times 10^{6}$ & 33,34 \\
\hline & & $\begin{array}{c}\text { Side } \\
\text { Zoom }\end{array}$ & $\begin{array}{l}11.5 \\
10.6 \\
\end{array}$ & 8.38 & 50 & 675 & 31 & $\begin{array}{c}\text { Side } \\
\text { Lo-res }\end{array}$ & 46 & 5.8 & 120 & $1.7 \times 10^{6}$ & 35 \\
\hline & & Spectrum & -- & 3 & 16.6 & -- & 32 & & & & & & \\
\hline \multirow{2}{*}{6} & \multirow{2}{*}{ TN-24P } & None & & & & & & Side & 53 & 6.8 & 60 & $0.5 \times 10^{6}$ & 37 \\
\hline & & Spectrum & -- & 3 & 16.6 & -- & 36 & & & & & & \\
\hline
\end{tabular}



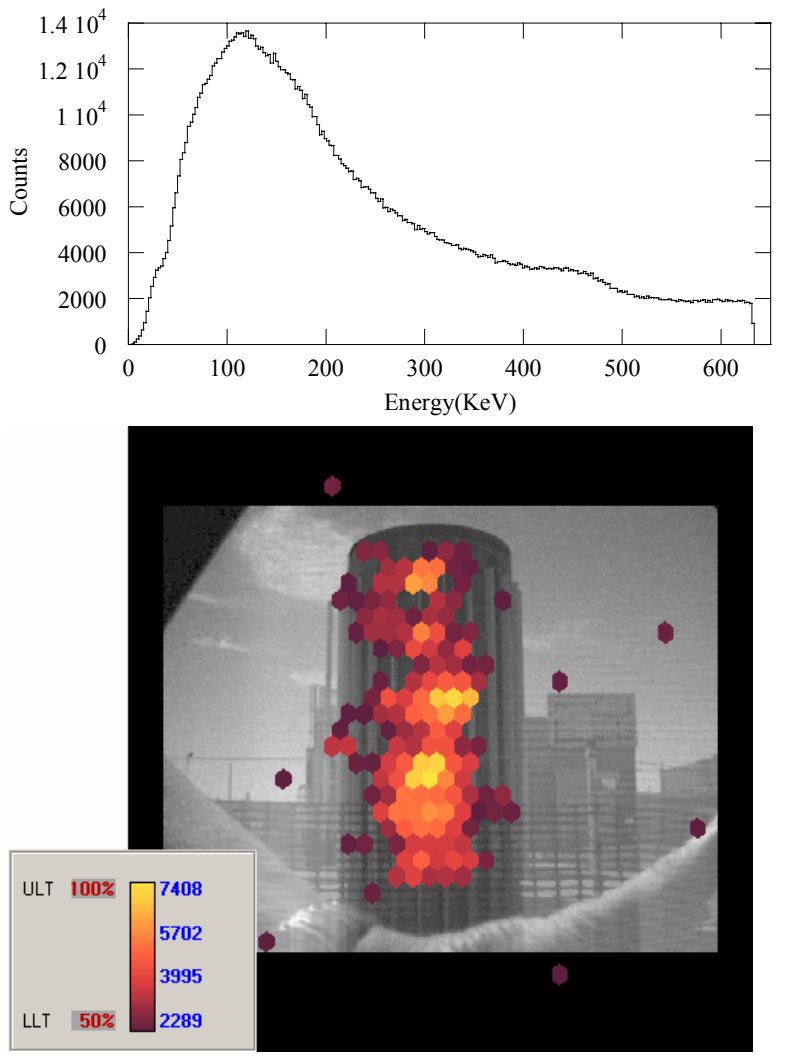

Fig. 12. First cask image (bottom) taken of cask 1 (MC-10) for a total integration time of 20 minutes. The pixels are $\sim 19 \mathrm{~cm}$ in size. The associated spectrum is also given (top).

platform. As there was no precision control to the height, this was monitored by measuring the distance to the ground of the first scissor pivot-point (see Fig. 16.)

The overhead data was collected in two runs of 70 and 90 minutes from a distance to the cask center of $3 \mathrm{~m}$. This provided a pixel size of $\sim 7.0 \mathrm{~cm}$. Note that the instrument was buffeted by the wind during the measurement. Lateral motions of $\sim 3 \mathrm{~cm}$ were observed. The data shown in Fig. 15 comprises the full duration of the runs. Partial playback, omitting the first $10 \%$ of the data to compensate for different lift times, did not qualitatively affect the images.

\section{Germanium Spectrometer Data}

The spectrum obtained from Cask 1 is shown in Fig. 17. It represents $1000 \mathrm{sec}$ of livetime with a deadtime fraction of $22.9 \%$. The MC-10 spectrum shows prominent gamma-ray lines of the fission products ${ }^{137} \mathrm{Cs},{ }^{60} \mathrm{Co}$ and ${ }^{154} \mathrm{Eu}$; and contains boron, calcium, hydrogen, iron and silicon neutron induced gamma-ray peaks as well.

\section{Neutron images}

In order to avoid crowding of the instruments, the neutron imaging measurements were performed in a differ-
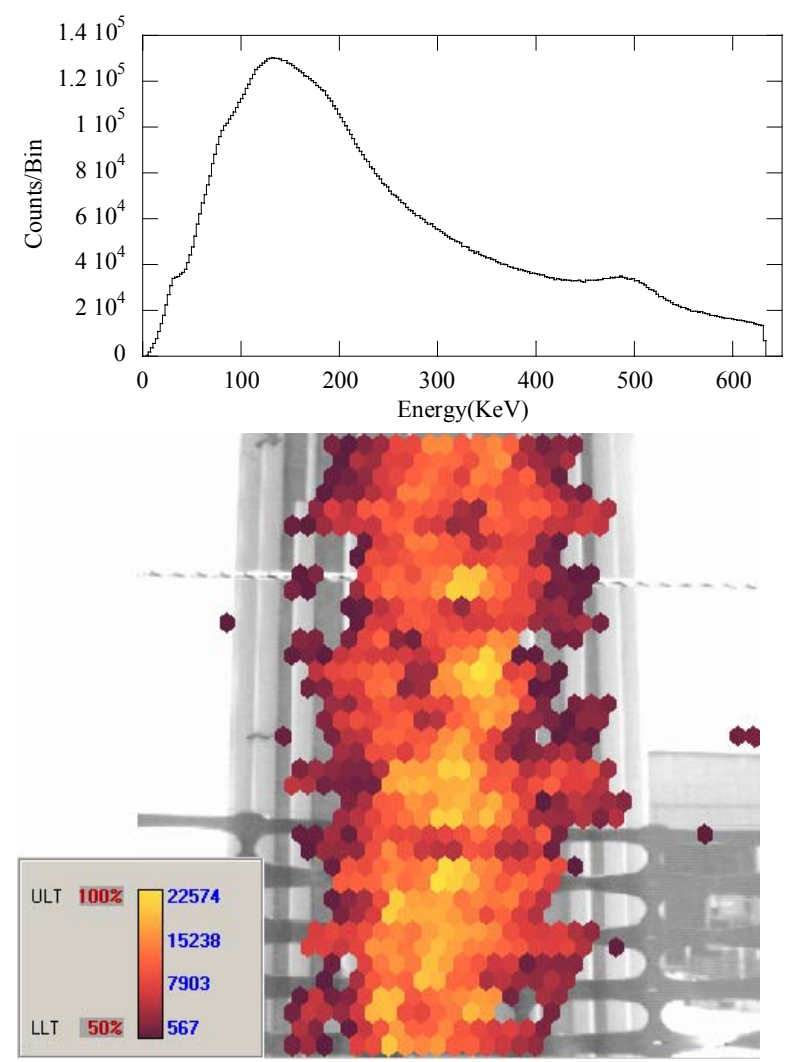

Fig. 13. Zoomed view of cask 1. The pixels are $\sim 13.5$ $\mathrm{cm}$ in size. The integration time was 3 hours.

ent sequence, but are reported here in the same cask order as the gamma imaging for comparison purposes. Cask MC-10 thermal neutrons were imaged last, from a distance of $8.12 \mathrm{~m}$ from the center of the cask with a $10-\mathrm{cm}$ focal length, using the " $\mathrm{A}$ " mask (19 x 19 pixels). The field of view was 12.2 meters, and a pixel corresponds to $64 \mathrm{~cm}$ in the source plane. The count rate was about 250 neutrons per second. Independent exposures of 60 minutes and 120 minutes, each, were acquired with the mask in both the normal and antimask rotations. The six hours of data were combined into a single image to minimize the random statistical fluctuations. Fig. 18 shows the final image with unsmoothed data binned into areas corresponding to $1 / 4$ of the mask pixel area. It is not clear whether fluctuations in intensity on the scale of one pixel show any significant features in the fuel assembly, because the image still contains a lot of statistical noise. A histogram of the pixel intensities from the unsmoothed image is shown in Fig. 19. Note that only a small fraction of the pixels have intensities greater than 150 , on a renormalized scale of $0-255$. These pixels represent the brightest and most significant regions of the image. However, they are still statistically noisy. Many of these fluctuations are minimized in the smoothed image (Fig. 20,) which shows the entire cask glowing fairly uniformly. 

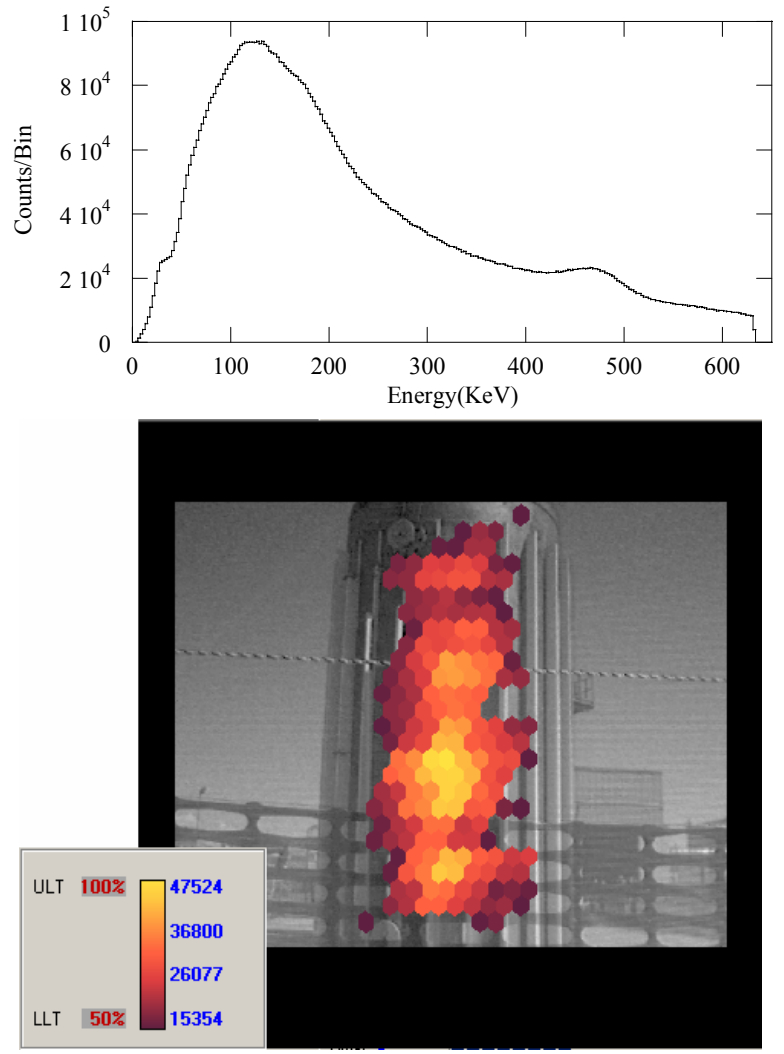

Fig. 14. Second wide-angle image of cask 1 and the associated spectrum. The pixels are $14 \mathrm{~cm}$ in size. The integration time was 2 hours.

\section{Cask 2: NuPac 125B}

Gamma-ray images

No Gamma-ray images of this cask were obtained.

\section{Ge Spectrometer}

The spectrum obtained from Cask 2 is shown in Fig. 21. It represents $1000 \mathrm{sec}$ of livetime with a deadtime fraction of $21.2 \%$. The NP-125B spectrum shows prominent gamma-ray lines of the fission products ${ }^{137} \mathrm{Cs}$, ${ }^{60} \mathrm{Co}$, and ${ }^{154} \mathrm{Eu}$; and it contains boron, calcium, hydrogen, iron, and silicon neutron-induced gamma-ray peaks as well.

\section{Neutron images}

No neutron images of this cask were obtained.

\section{Cask 3: GNS V/21}

Gamma-ray images

Images of Cask 3, the Castor V/21, were obtained on the last day of measurements. The first two exposures were obtained from the south side of the pad. Both of these showed poor mask/anti-mask balance. This was traced to the make-shift cinderblock arrangement to shield the imager from the sun. In the early morning the relative sun motion required moving the sun-shield
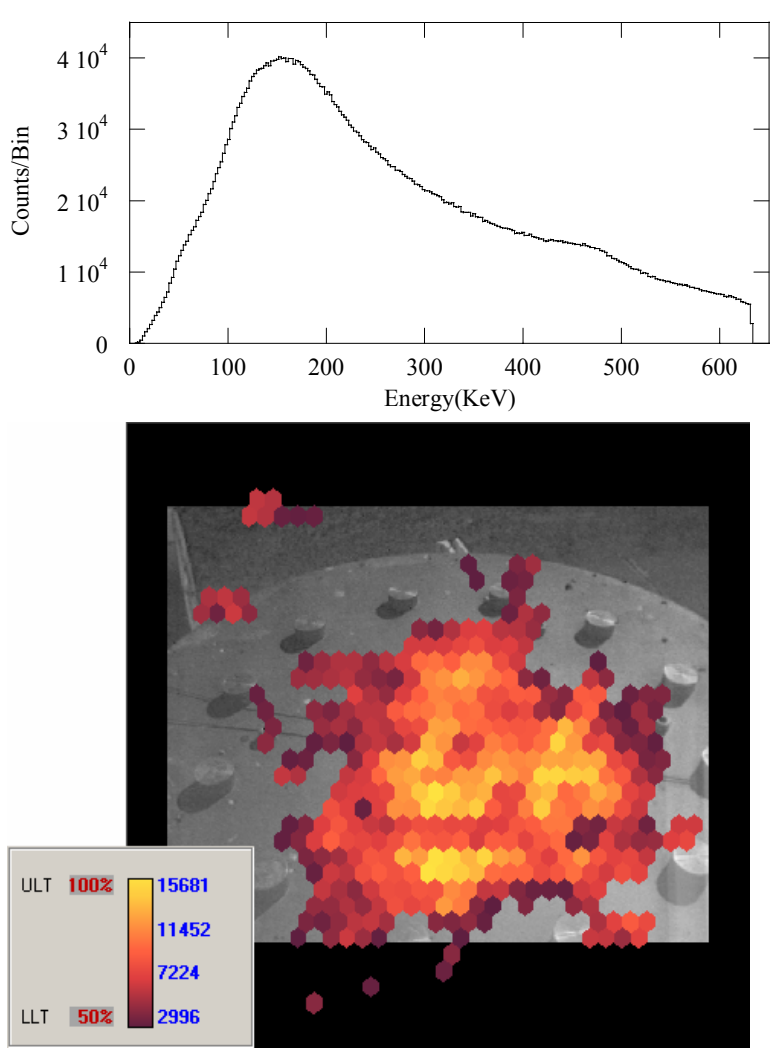

Fig. 15. Overhead view of Cask 1. The pixels are $\sim 6.8$ $\mathrm{cm}$ in size. The total integration time was 160 minutes. Note the difference in the spectrum between this view and that obtained from the side.

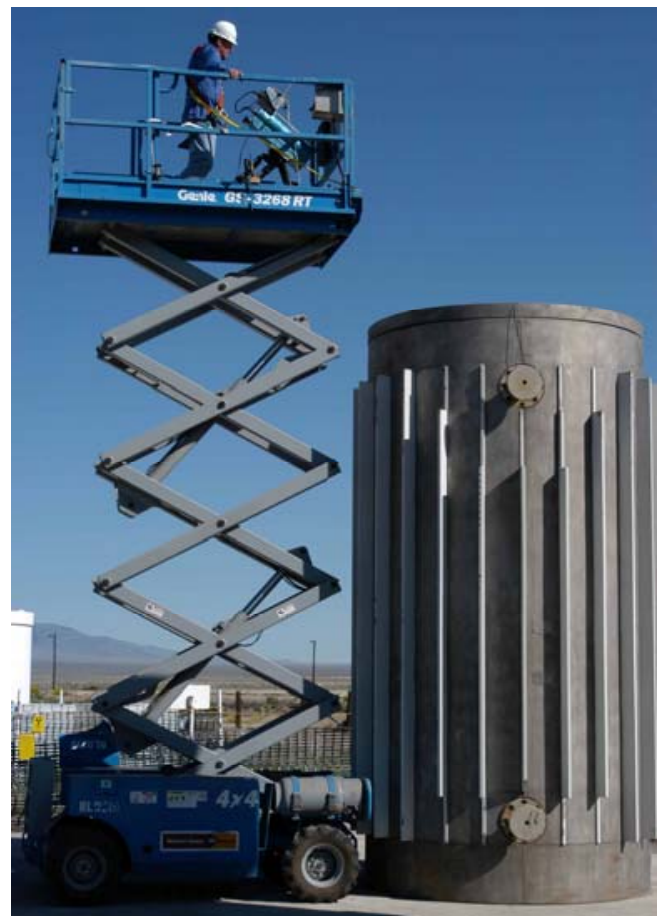

Fig. 16. The lift used to take top-down images of Cask 1. 


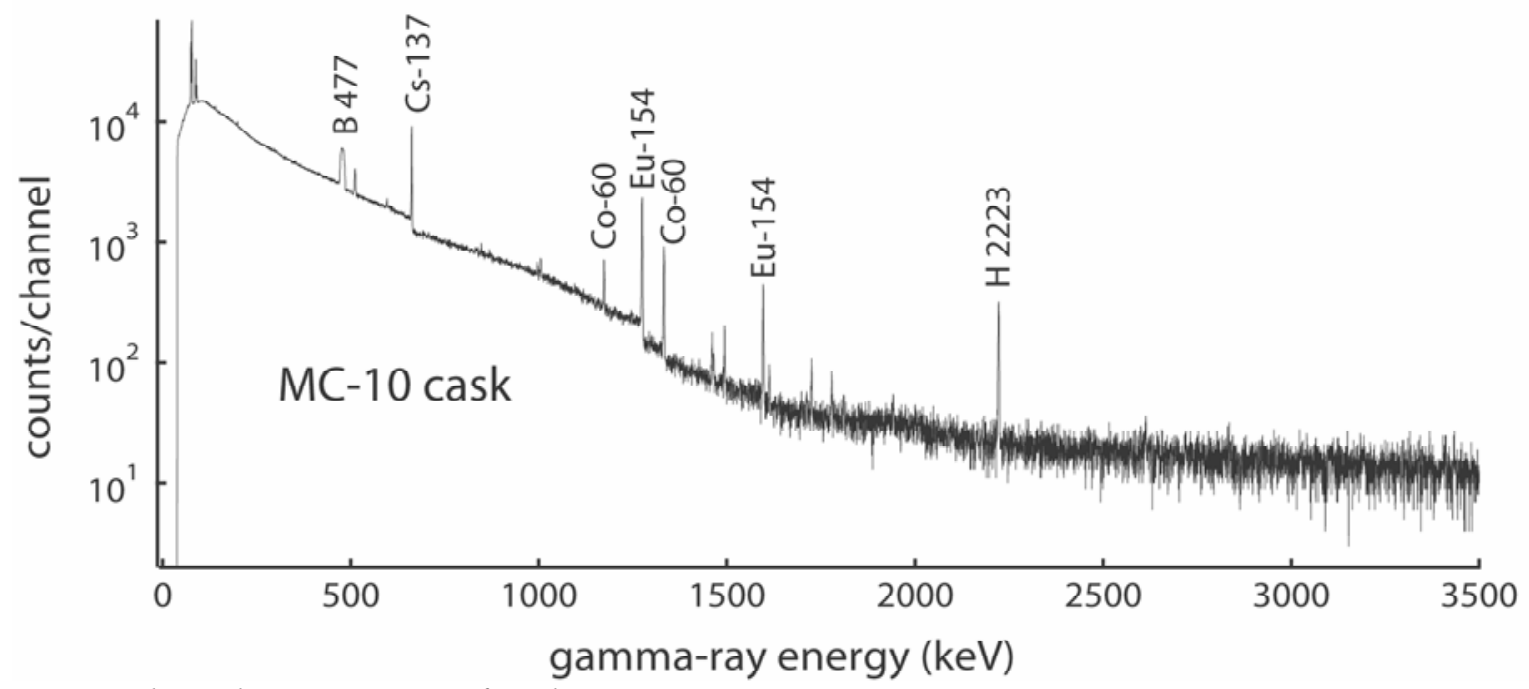

Fig. 17. High resolution spectrum of Cask 1 .

more frequently and to a greater extent. Unfortunately, this also meant moving the cinderblock used to keep the contrivance from blowing away in the wind. In moving the cinderblock, we changed the shielding configuration of the system and unbalanced the mask/anti-mask integrations.

A second attempt to image Cask 3 was performed from the North side. This resulted in the image in Fig. 22. The pixel size in the image is $\sim 13.6 \mathrm{~cm}$. Note that the image was very noisy so that the gamma-ray threshold is set to $60 \%$ of the maximum level rather than the $50 \%$ used in other images. The morphology of the image is consistent with radiation coming out the bottom of the cask and scattering off of the ground. It is not clear why the contrast is so poor in the image. The number of

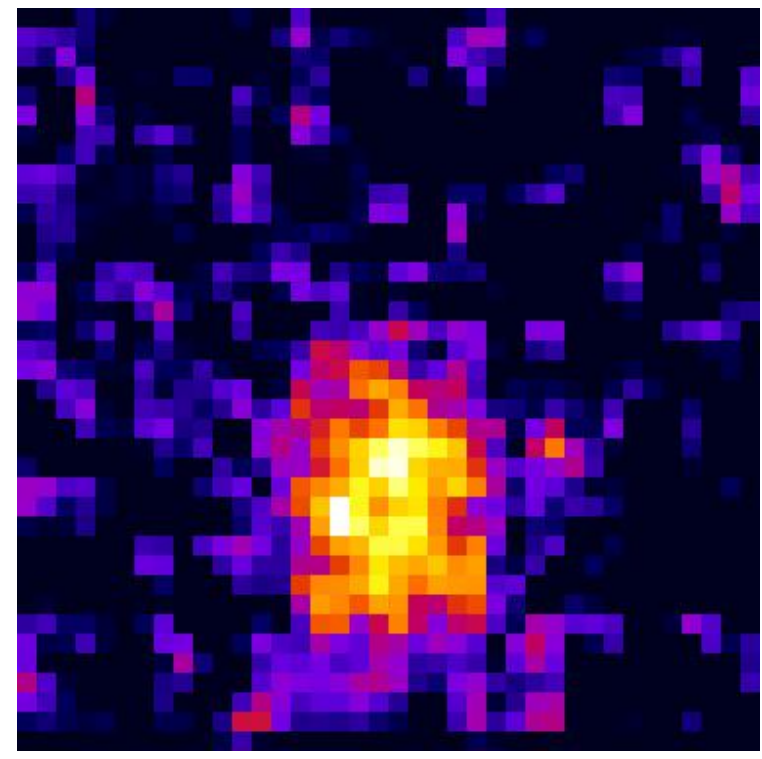

Fig. 18. Thermal-neutron image of cask MC-10 processed in bins equal to $1 / 4$ of a mask pixel area.

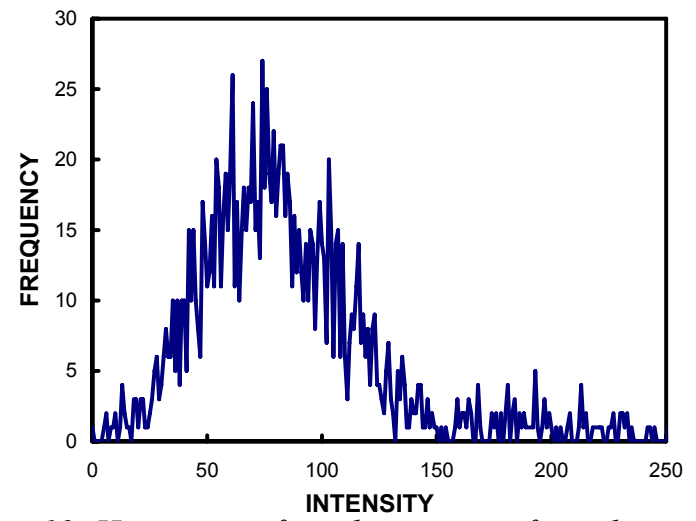

Fig. 19. Histogram of pixel intensities from data in the unsmoothed image.

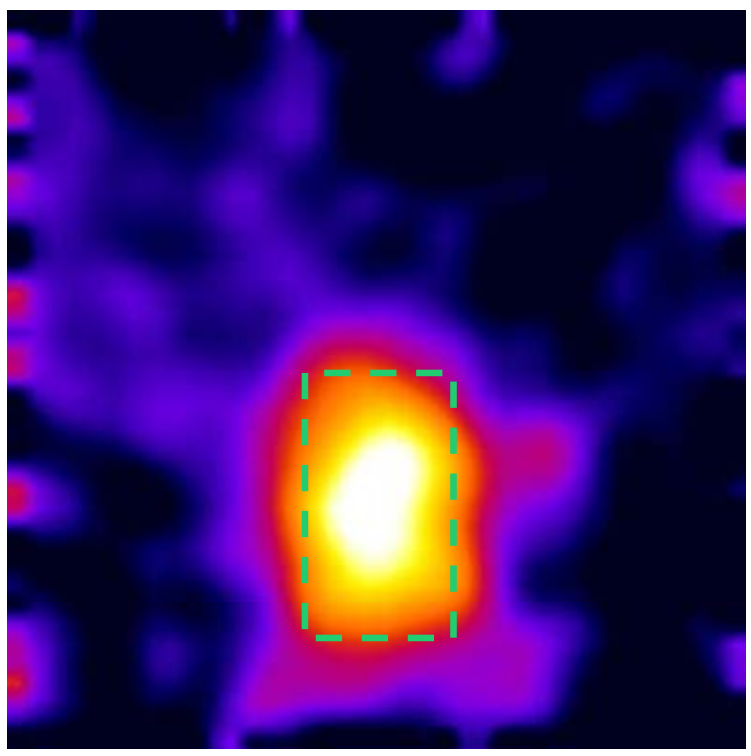

Fig. 20. Smoothed neutron image of cask 1 with the green rectangle indicating the size of the cask 


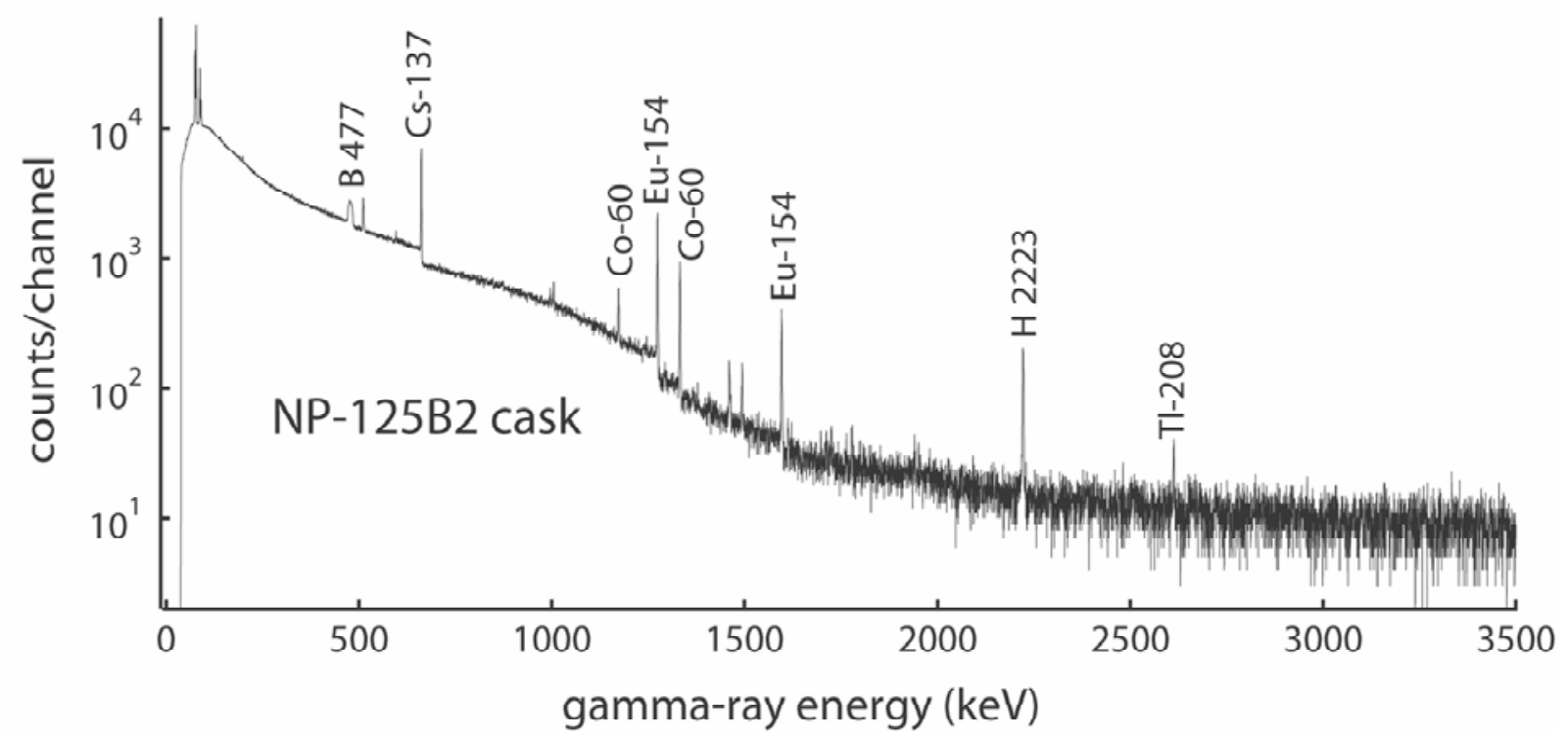

Fig. 21. Spectrum of Cask 2.

events in the image is $3.46 \times 10^{6}$, a number commensurate with other higher-contrast images. Unfortunately, a background rate at the location was not obtained. It is possible that the neighboring casks produced a large
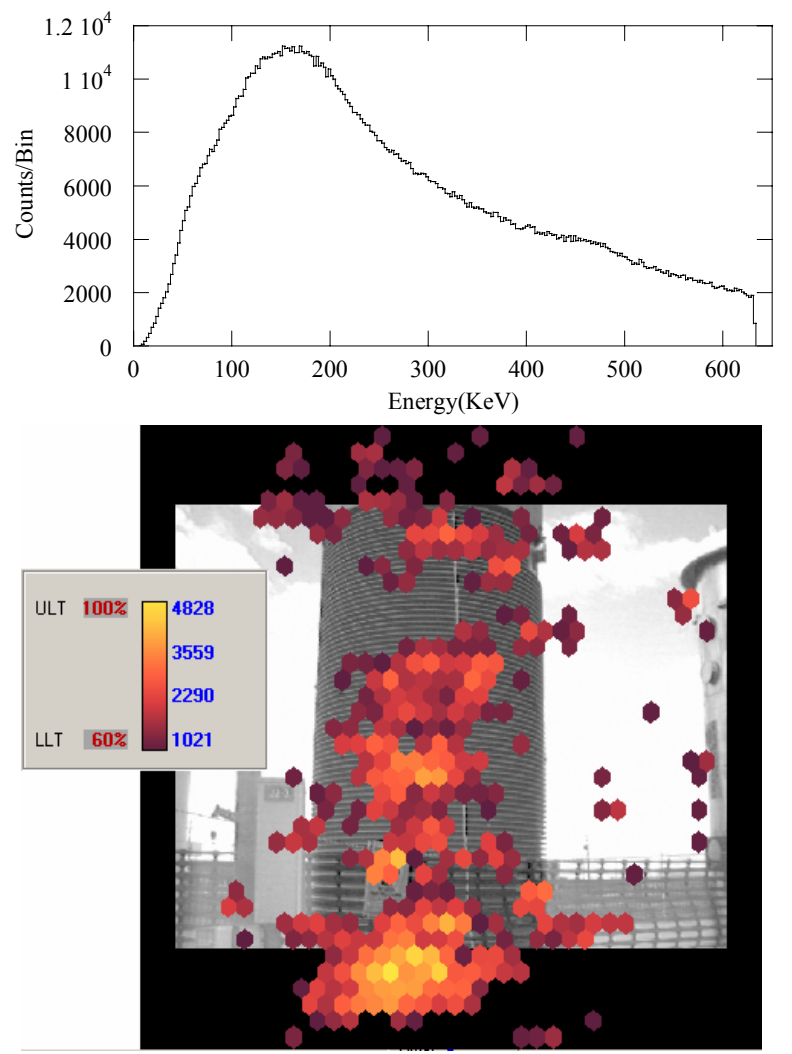

Fig. 22. Wide-field Image of Cask 3. The gamma-ray threshold in this image is set to $60 \%$ of the maximum intensity. The pixel size is $\sim 13.6 \mathrm{~cm}$ and the integration time was one hour. fraction of the counts from radiation that penetrated the $0.95 \mathrm{~cm}$ thick $\mathrm{Pb}$ shielding around the detector. This amounts to $\sim 0.8$ mean free paths at $662 \mathrm{keV}$.

\section{Germanium Spectrometer Data}

The spectrum obtained from Cask 3 is shown in Fig. 23. It represents $1000 \mathrm{sec}$ of livetime with a deadtime fraction of $21.2 \%$. The $\mathrm{V} / 21$ spectrum shows prominent gamma-ray lines of the fission products ${ }^{137} \mathrm{Cs},{ }^{60} \mathrm{Co}$, and

${ }^{154} \mathrm{Eu}$; and it contains boron and hydrogen neutroninduced gamma-ray peaks as well.

\section{Neutron image}

Cask 3 was imaged with the "A" mask in the normal position over an acquisition period of 15 hours. The resulting smoothed image, shown in Fig. 24, suggests a dark vertical band in the center of the image, with brighter regions at the edges. The contrast is weak, and could be affected by imaging artifacts, but at face value it indicates that the cask is heavily shielded for thermal neutron leakage, so that it looks darker than the surrounding background of neutrons scattered in the atmosphere. A 1-hour antimask image was also acquired, but those data contained more statistical noise than the overnight run and, after scaling the data appropriately, the combined mask-antimask image was washed out (Fig. 25.) Clearly, the mask and antimask data should be acquired for the same time for optimal results.

\section{Cask 4: REA-2023}

Gamma-ray images

The gamma-ray image of cask 4 was obtained from the north side of the pad at a distance of $6.0 \mathrm{~m}$. A single wide-field image (see Fig. 26) was obtained in 60 minutes total integration time. The approximate resolution is $13.5 \mathrm{~cm}$ per pixel. A total of $3.46 \times 10^{6}$ counts were 


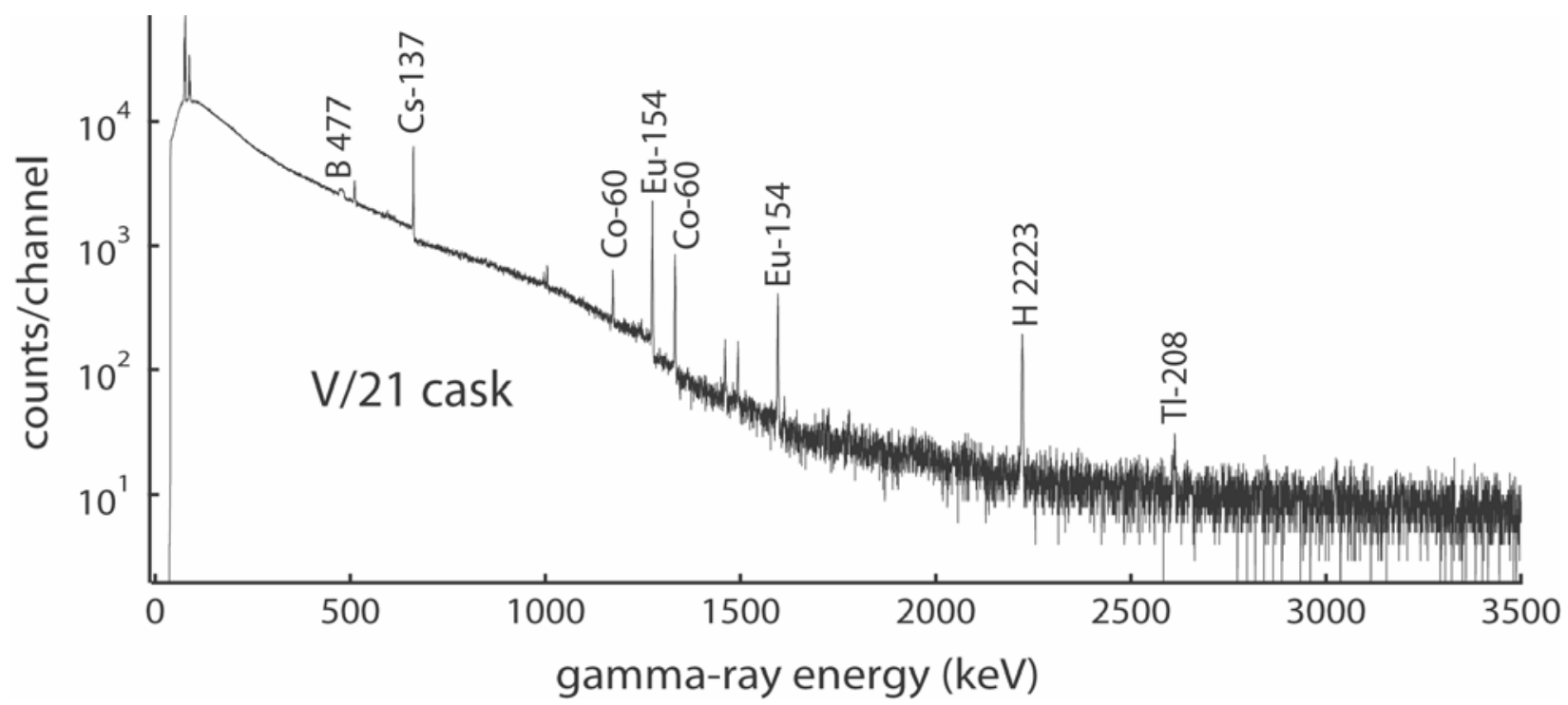

Fig. 23. Spectrum from Cask 3.

recorded by the imager. The image clearly shows that the radiation is confined to the central region of the cask and is uniform along its length. However, the contrast in the image is relatively low.

\section{Germanium Spectrometer Data}

The spectrum obtained from Cask 4 is shown in Fig. 27. It represents $1000 \mathrm{sec}$ of livetime with a deadtime fraction of $22.9 \%$. The REA-2023 spectrum shows prominent gamma-ray lines of the fission products. ${ }^{137} \mathrm{Cs},{ }^{60} \mathrm{Co}$, and ${ }^{154} \mathrm{Eu}$; and it contains boron, hydrogen, and iron neutron-induced gamma-ray peaks as well.

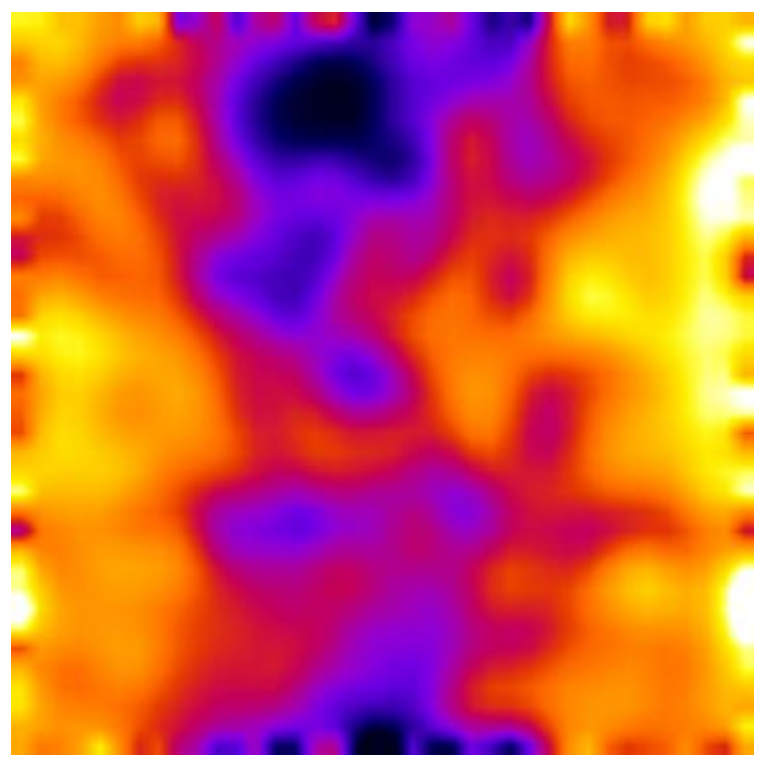

Fig.24. Smoothed, 15-hr, neutron image of cask 3 with mask-only data. The cask emits a lower flux of neutrons than from the surrounding area.

\section{Neutron image}

The combined mask-anti-mask image obtained for cask 4 is shown in Fig. 28 after smoothing and contrast enhancement. The bright vertical stripe in the middle of the image is much narrower than the exterior dimensions of the cask (shown in green dashes.) This appearance may be somewhat exaggerated by the thresholding effect of the false colors, but is consistent with the gamma-ray image in Fig 26, which is also narrow. A horizontal profile of the neutron intensity (see Fig. 29) does not show a sharp edge for the bright region, but is slightly more peaked than a cosine distribution that one might expect for transmission through an annular absorber.

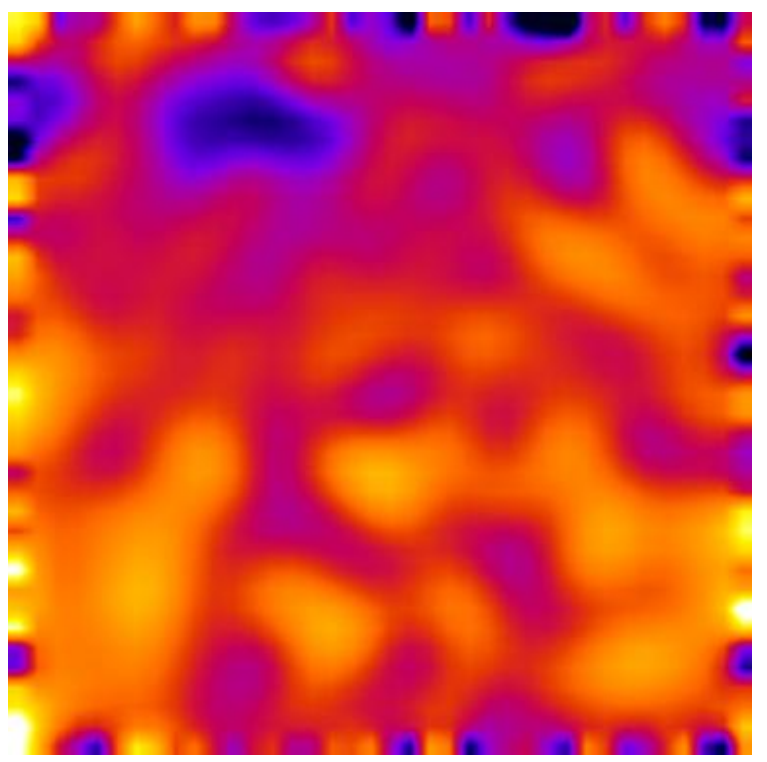

Fig. 25. Smoothed neutron image of Cask 3 after subtracting 1-hr anti-mask data having poorer statistics than the overnight run. 

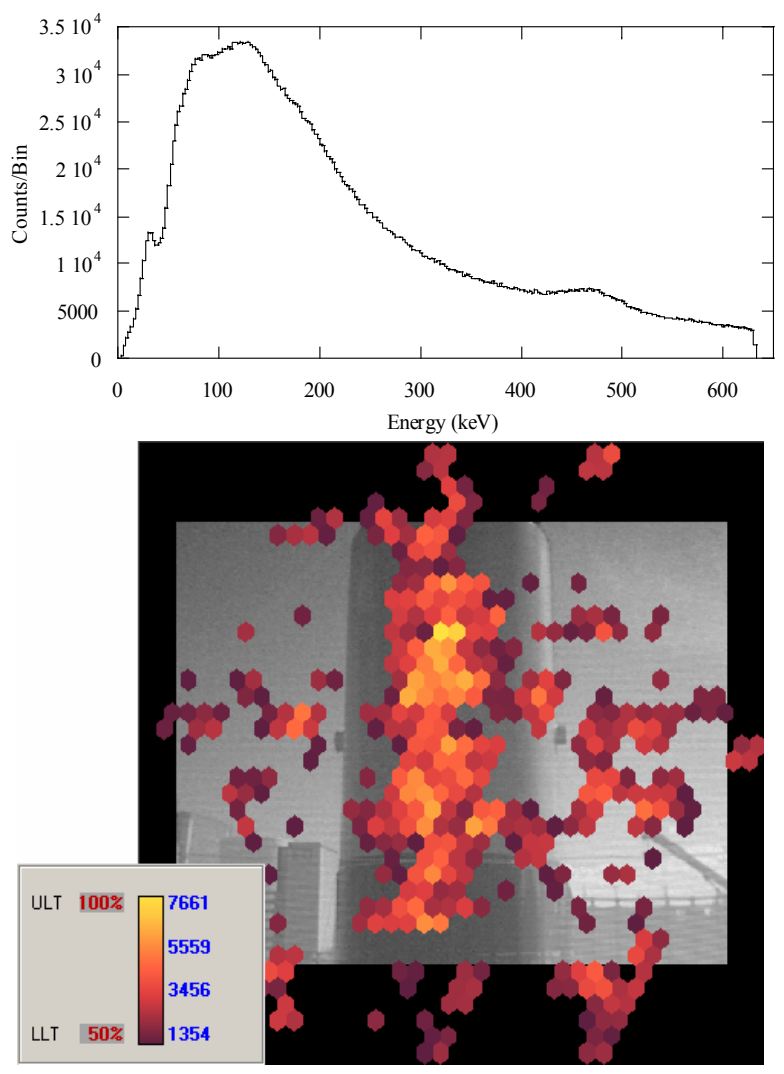

Fig. 26. Wide-angle image of cask 4 and the associated spectrum. The pixel size is $\sim 13.5 \mathrm{~cm}$ and the integration time was 1 hour.

\section{Cask 5: VSC-17}

Gamma-ray images

Two images of cask 5, the Pacific Sierra Nuclear VSC17 , were obtained. Both were obtained from a distance of $8.38 \mathrm{~m}$. The first was a wide-angle image with a total exposure time of one hour and a pixel size of $\sim 18.5$ $\mathrm{cm}$. It is shown in Fig. 30. A zoomed image with an

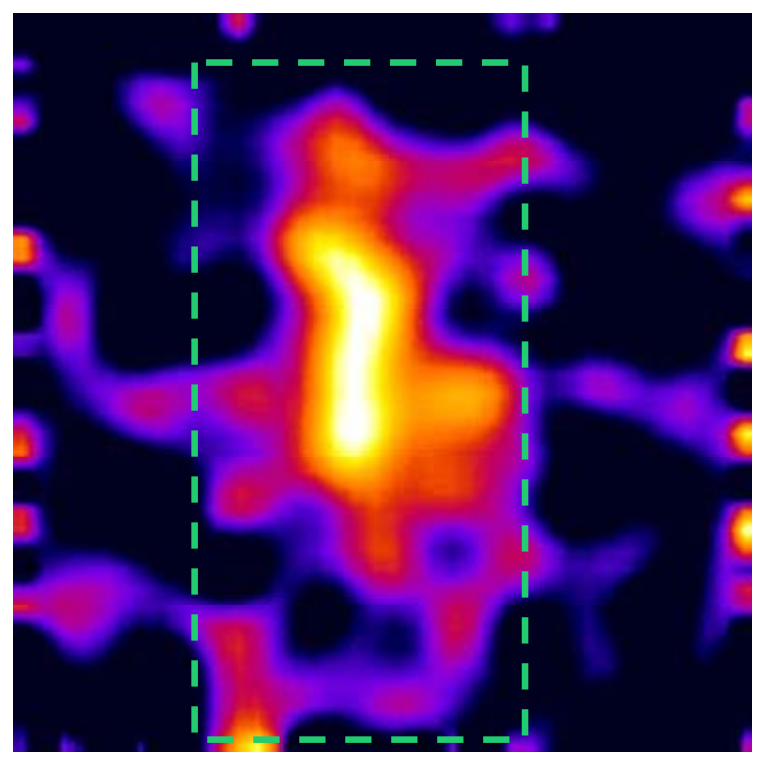

Fig. 28. Smoothed mask-antimask neutron image of cask 4 .

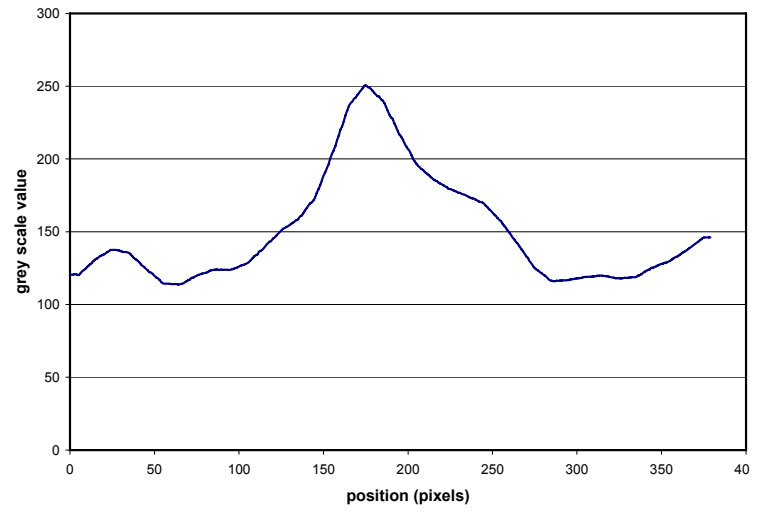

Fig. 29. Intensity profile across the image of cask 4.

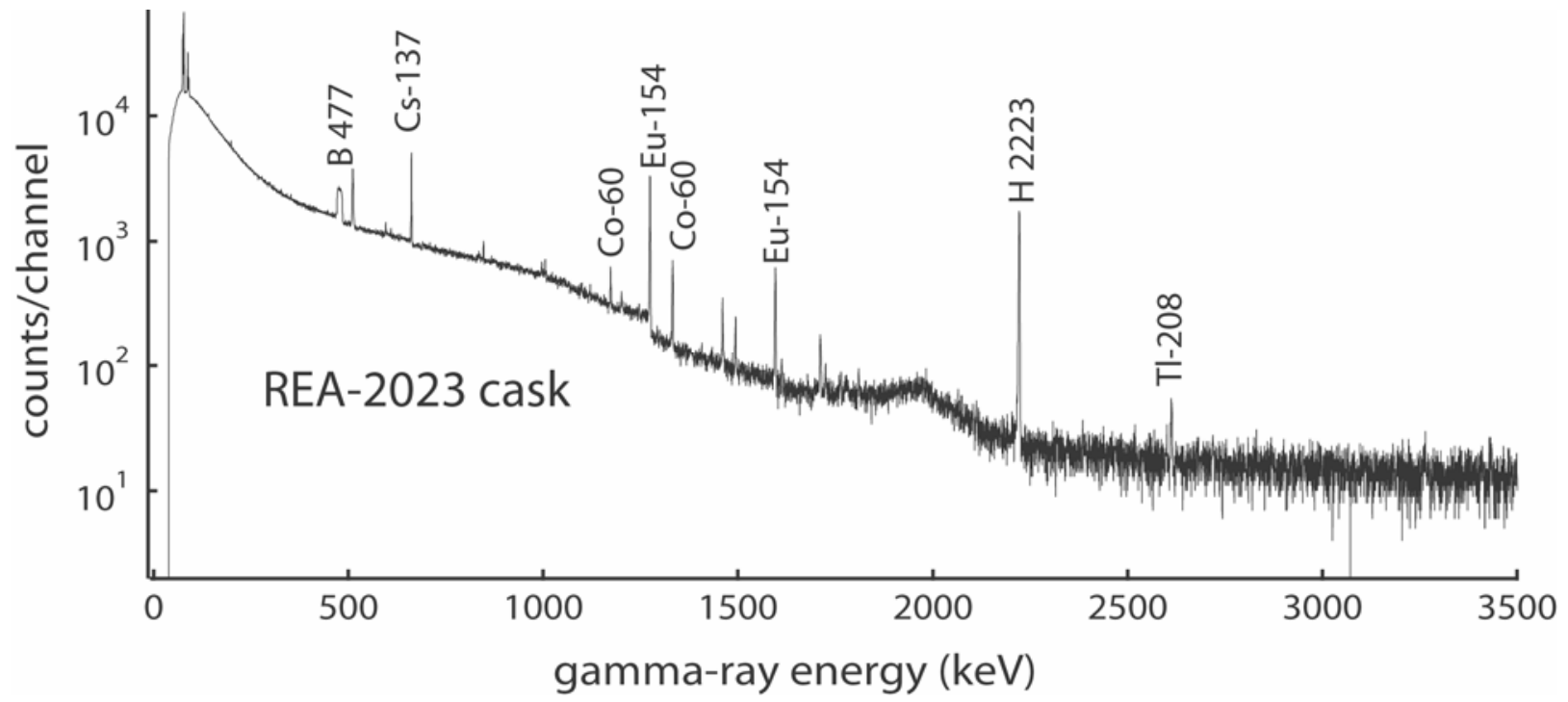

Fig. 27. Spectrum obtained from cask 4. Note that this is for 2000 sec. livetime, twice that of the other spectra. 

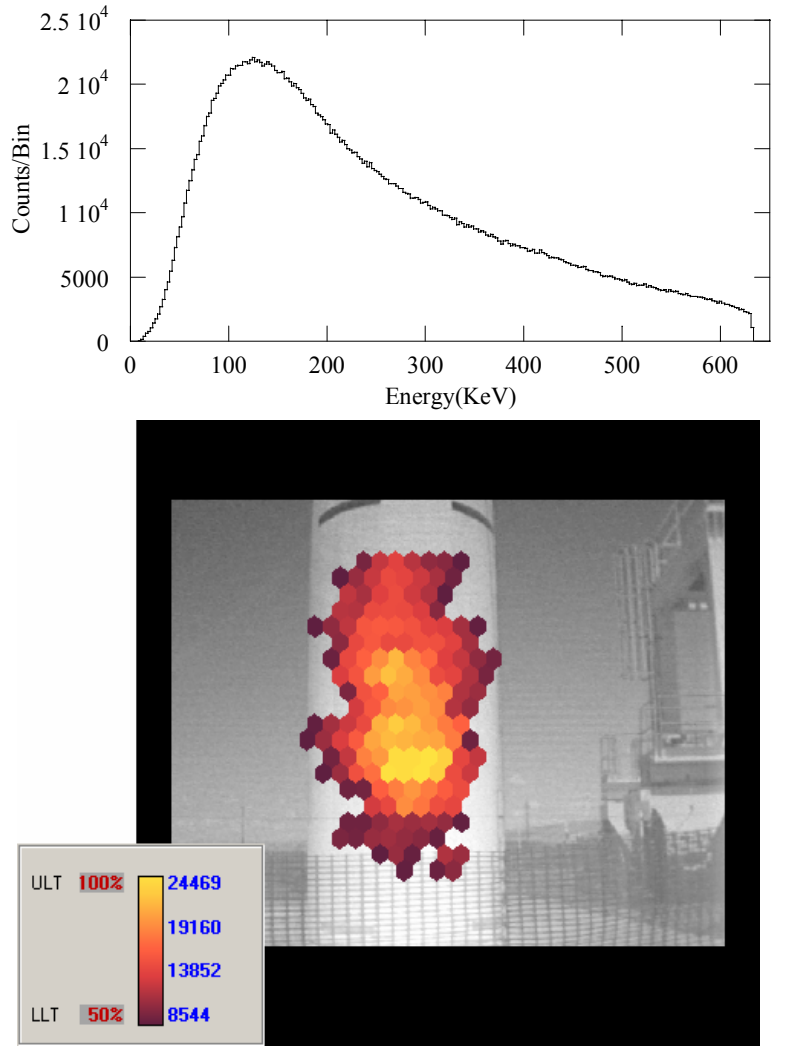

Fig. 30. Wide-angle image of cask 5 and the associated spectrum. The pixel size is $\sim 18.5 \mathrm{~cm}$ and the integration time was 1 hour.

average pixel size of $11 \mathrm{~cm}$ is shown in Fig. 31. This data represents $43 \mathrm{~min}$. out of the total $60 \mathrm{~min}$. integration. The imager was bumped during the last 10 minutes of the anti-mask run. Consequently only the first $71 \%$ of each file was replayed to obtain the image shown. The gamma-ray images clearly show a bright region that is centered on the cask horizontally and it appears hotter near the bottom of the cask.
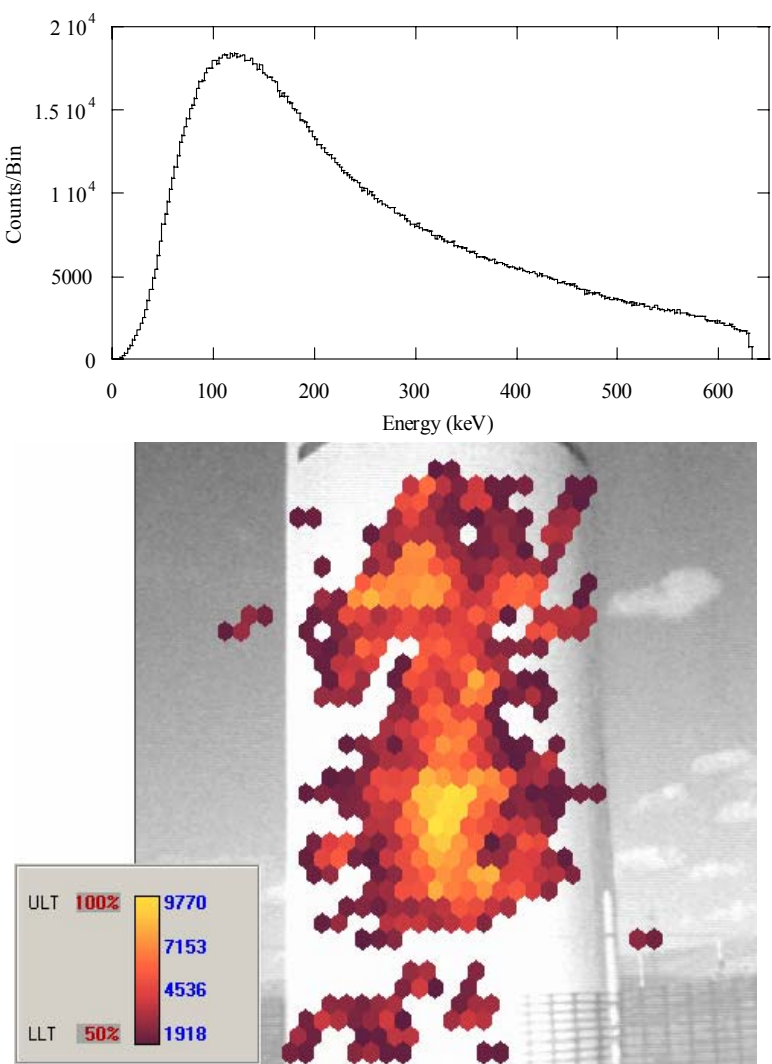

Fig. 31. Zoomed view of Cask 5. The pixel size is $\sim 11$ $\mathrm{cm}$ and the integration time was 43 minutes.

\section{Spectrometer Data}

The spectrum obtained from Cask 5 is shown in Fig. 32. It represents $1000 \mathrm{sec}$ of livetime with a deadtime fraction of $26.1 \%$. The VSC-17 spectrum shows prominent gamma-ray lines of the fission products ${ }^{137} \mathrm{Cs}$, ${ }^{60} \mathrm{Co}$, and ${ }^{154} \mathrm{Eu}$; and it contains calcium, hydrogen, iron, and silicon neutron-induced gamma-ray peaks as well.

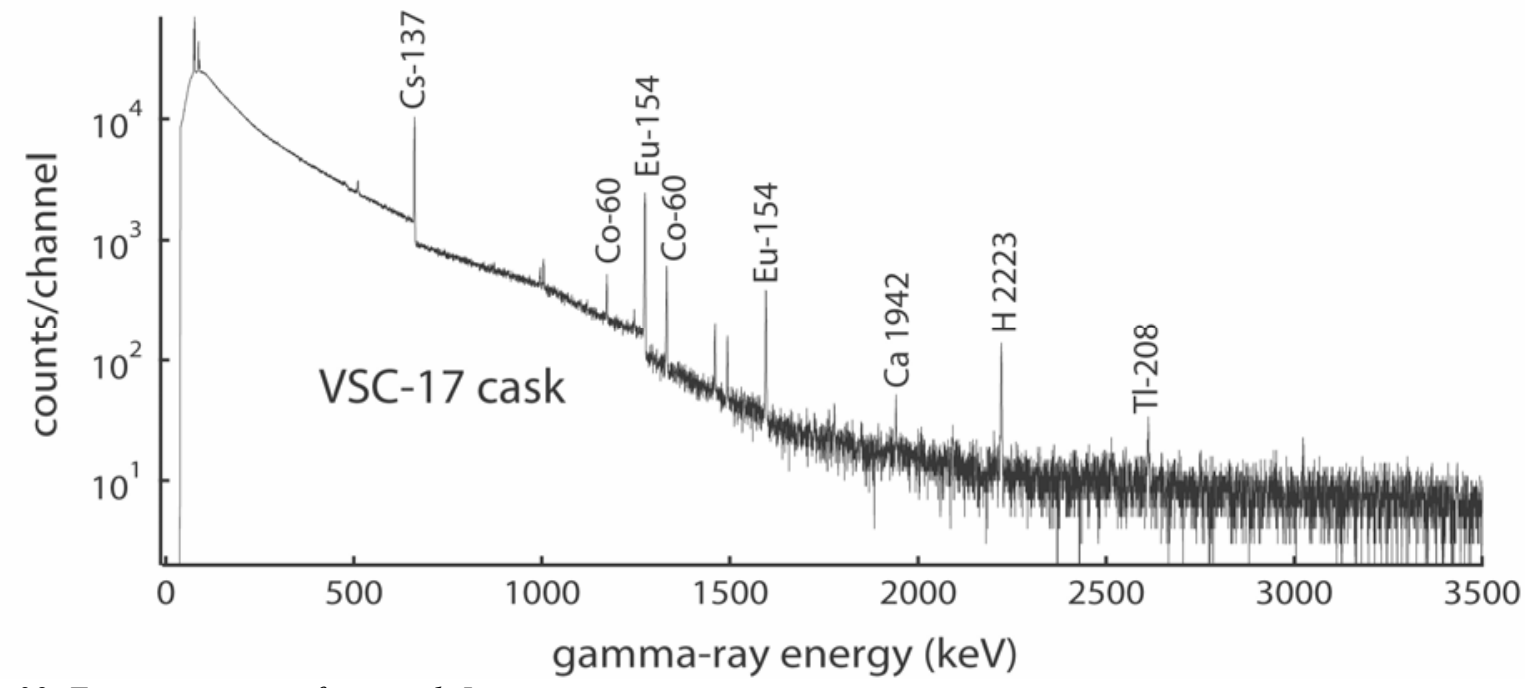

Fig.32. Energy spectrum from cask 5. 


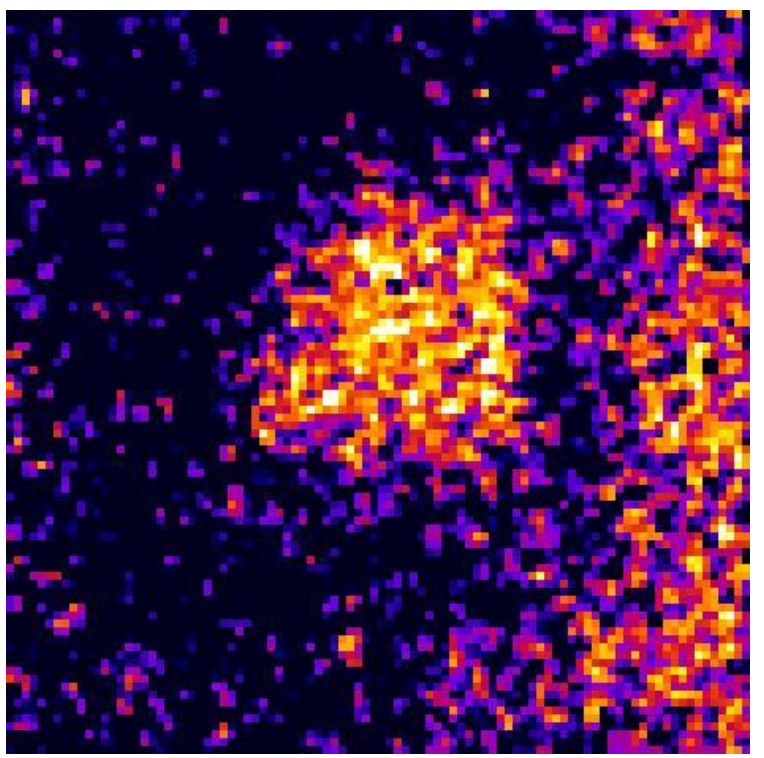

Fig.33. Neutron image of cask 5 using $47 \times 47$ pixel mask, binned into areas corresponding to $1 / 4$ of a mask pixel.

Neutron image

The image in Fig. 33 was an attempt to obtain the best spatial resolution with mask " $\mathrm{C}$ ". One consequence of choosing small pixels is that the counts in each pixel become smaller relative to the statistical uncertainty derived from the total number of counts in the image. Subsequent smoothing can improve the image quality, as shown in Fig. 34, but long exposures are necessary before the smaller features in such images are considered significant.

In these two images, a bright region is seen at the right side of the picture, possibly due to partially encoded neutron flux coming from outside the primary field of view. In subsequent mask-antimask images acquired from the same position using lower resolution, this artifact was eliminated (Fig. 35.)

\section{Cask 6: TN-24P}

Gamma-ray images

No gamma-ray images of this cask were obtained.

\section{Ge spectrometer}

The spectrum obtained from cask 6 is shown in Fig 36 . It represents 1000 seconds of livetime with a deadtime fraction of $18.7 \%$. The TN-24P spectrum shows prominent gamma-ray lines of the fission products ${ }^{137} \mathrm{Cs}$, ${ }^{60} \mathrm{Co}$, and ${ }^{154} \mathrm{Eu}$; and it displays calcium, hydrogen, and silicon neutron-induced gamma-ray peaks as well.

\section{Neutron image}

Cask 6 was the first one to be imaged with the neutron camera, and attempts were made both with the "C" and

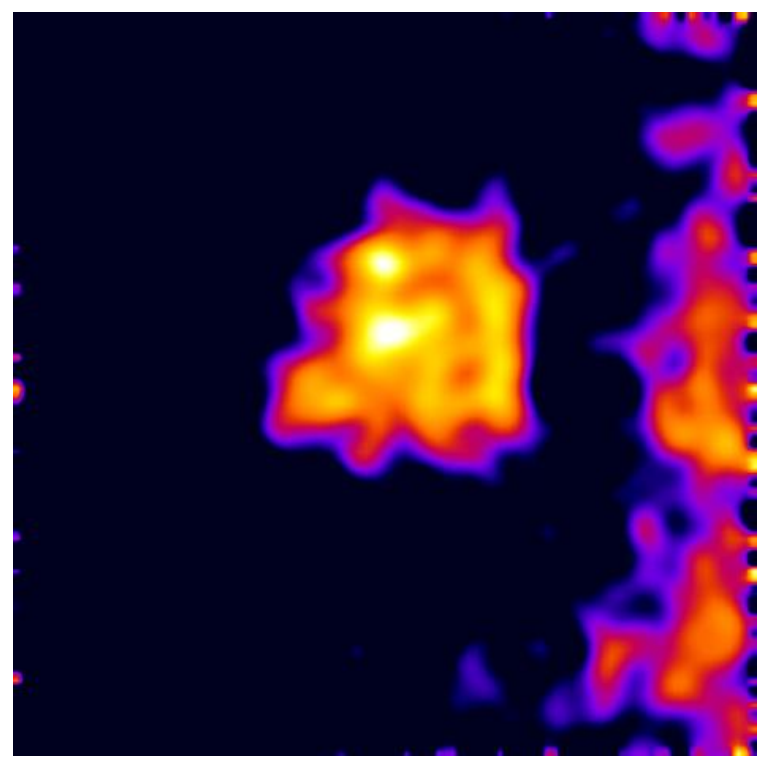

Fig. 34. Smoothed and thresholded neutron image of cask 5 using " $C$ " mask.

"A" masks. In neither case was an interesting or meaningful shape discerned in the images (see Fig. 37.) This cask appears to emit relatively few thermal neutrons.

\section{Discussion}

The primary goal of the project was to determine if cask fingerprinting is a viable technique. To this end, the images obtained with the two systems clearly demonstrate the proof-of-principle that the radiation fields emitted by the casks can be imaged. They also demonstrate that the fields are different depending on the cask

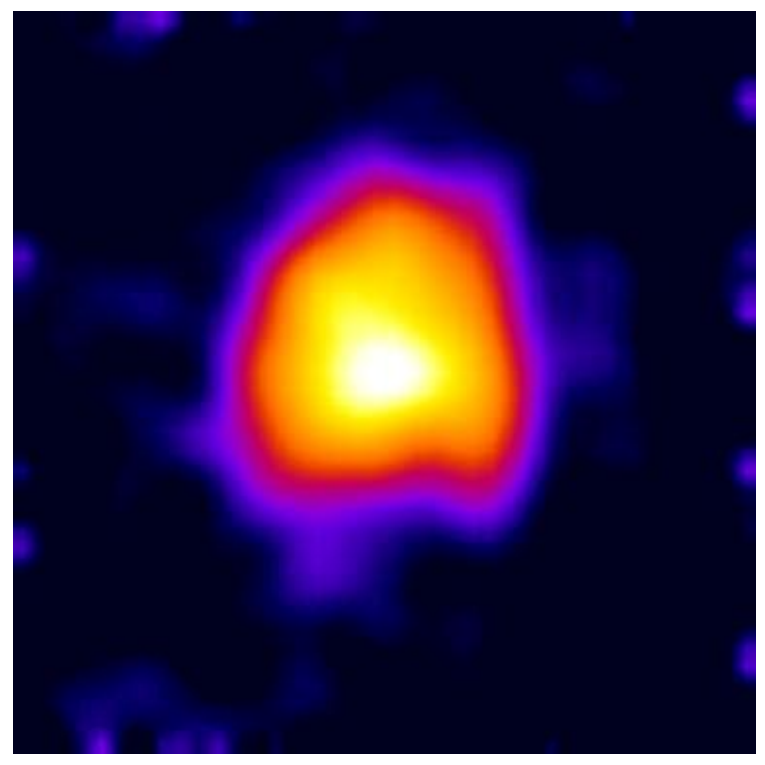

Fig. 35. Mask-antimask image of cask 5 using $19 \times 19$ pixel mask, with smoothing and thresholding. 


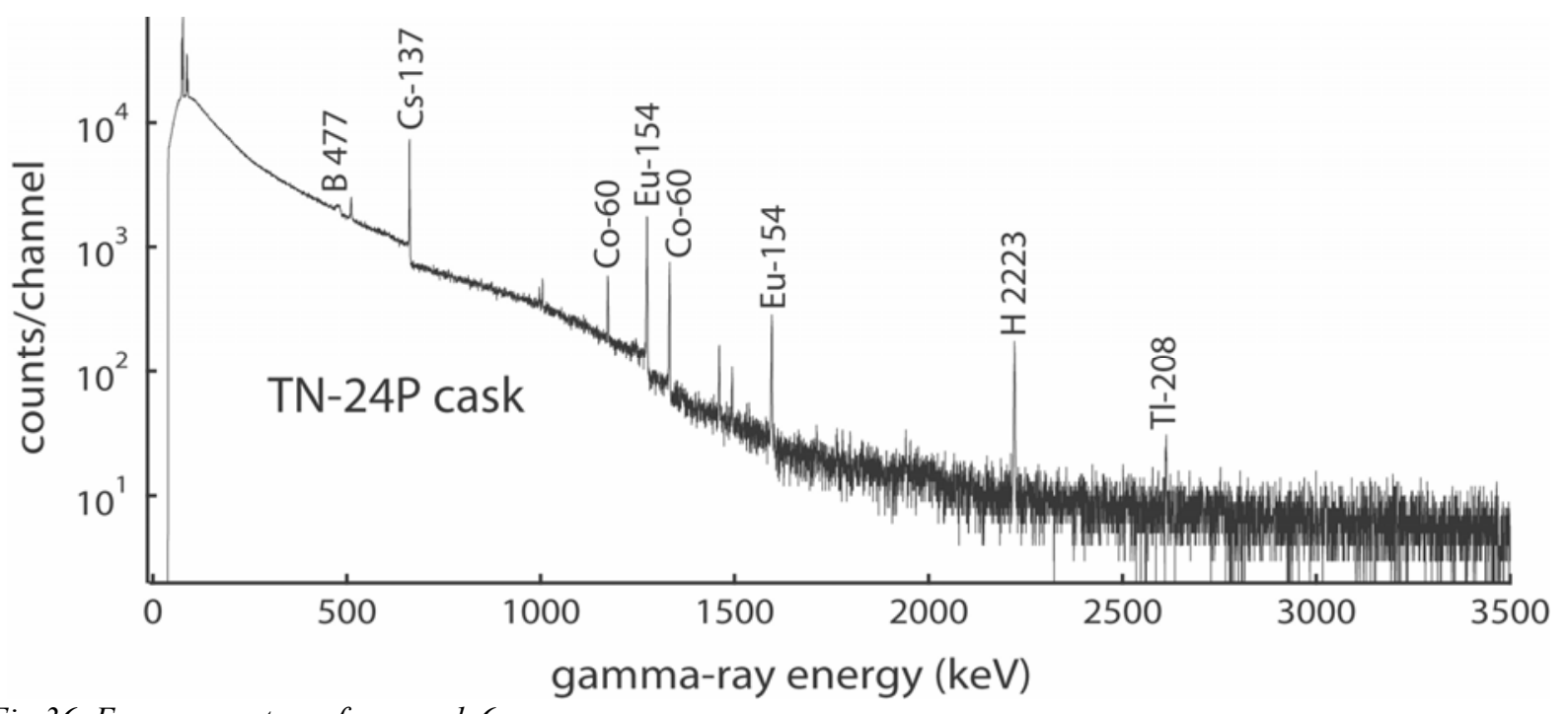

Fig.36. Energy spectrum from cask 6.

type.

\section{Gamma-Ray Results}

In Fig. 38 we provide a side-by-side comparison of the wide-field, whole-cask images obtained with the gamma-ray imager. To the right and below each of the false-color images is a histogram of the counts per pixel for the pixels that fall under the yellow cursor lines in the main image. These plots can be used to obtain a better idea of the signal-to-noise ratio and provide further information on the overall shape of the images. From the figure, it is clear that the overall morphology of the radiation fields vary significantly. For instance casks 1 and 5 provide intense radiation from the central regions of the cask while casks 3 and 4 have relatively

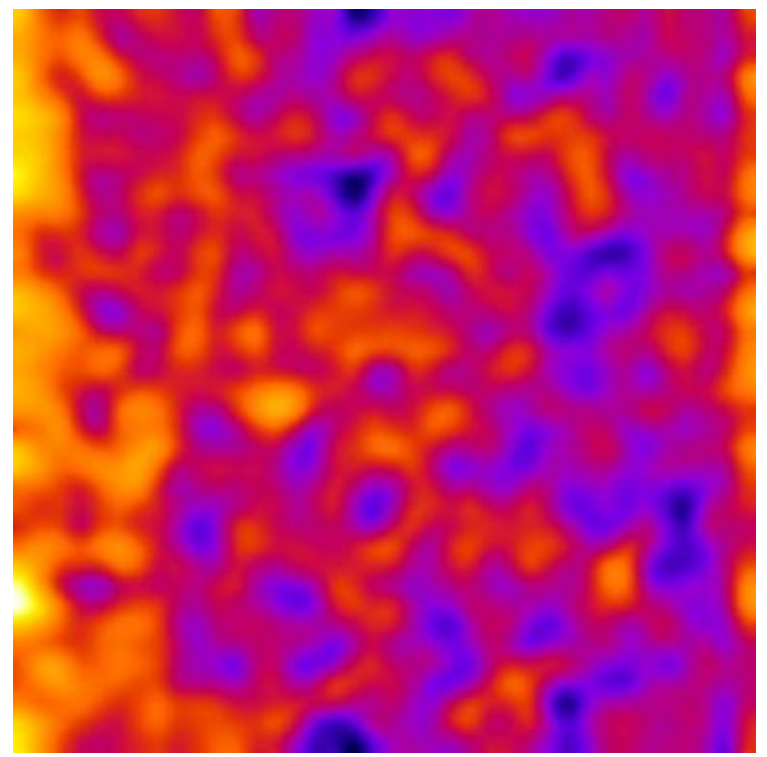

Fig. 37. Neutron image data from cask 6. This cask appeared to be weak in thermal neutron output. poor contrast. The image of cask 3 is suggestive of fuel being stored at the very bottom of the cask. This pattern is actually attributed to radiation leakage from the poorly shielded cask bottom and its subsequent scatter into the line of sight of the gamma-ray imager.

In fact, it would appear that scattered radiation dominates all of the images obtained with the gamma-ray imager. This is not surprising given that one of the primary cask functions is to shield the surroundings from the radiation emitted by the cask contents. As mentioned in the introduction, one expects the observed radiation pattern to have both a scattered and an unscattered component. One also expects that these two images should be separable based on energy cuts. This concept is validated by the data from the germanium spectrometer that clearly shows photopeaks are detected in the gamma-ray flux.

The spectral data is summarized in Table 3 . The numerical analysis shows that some of these peaks have excellent signal-to-noise ratios. Hence an image made of the line-radiation should provide clear images of the fuel assemblies. Unfortunately, the peaks are all above the useful energy range of the current imager. This shortcoming arises from the use of an extant imager to undertake the measurements and is not a fundamental limitation of the imaging techniques.

When taken together, the spectrometer data and the gamma-ray images obtained, show significant promise that the fingerprinting technique can be used. Most of the images are just what one would expect for the scattered component of the gamma-ray field. The images show the overall location of the sources, but with all detail washed out by the scattering process. Hence, the top view of cask 1 (Fig. 15) shows the elliptical shape 

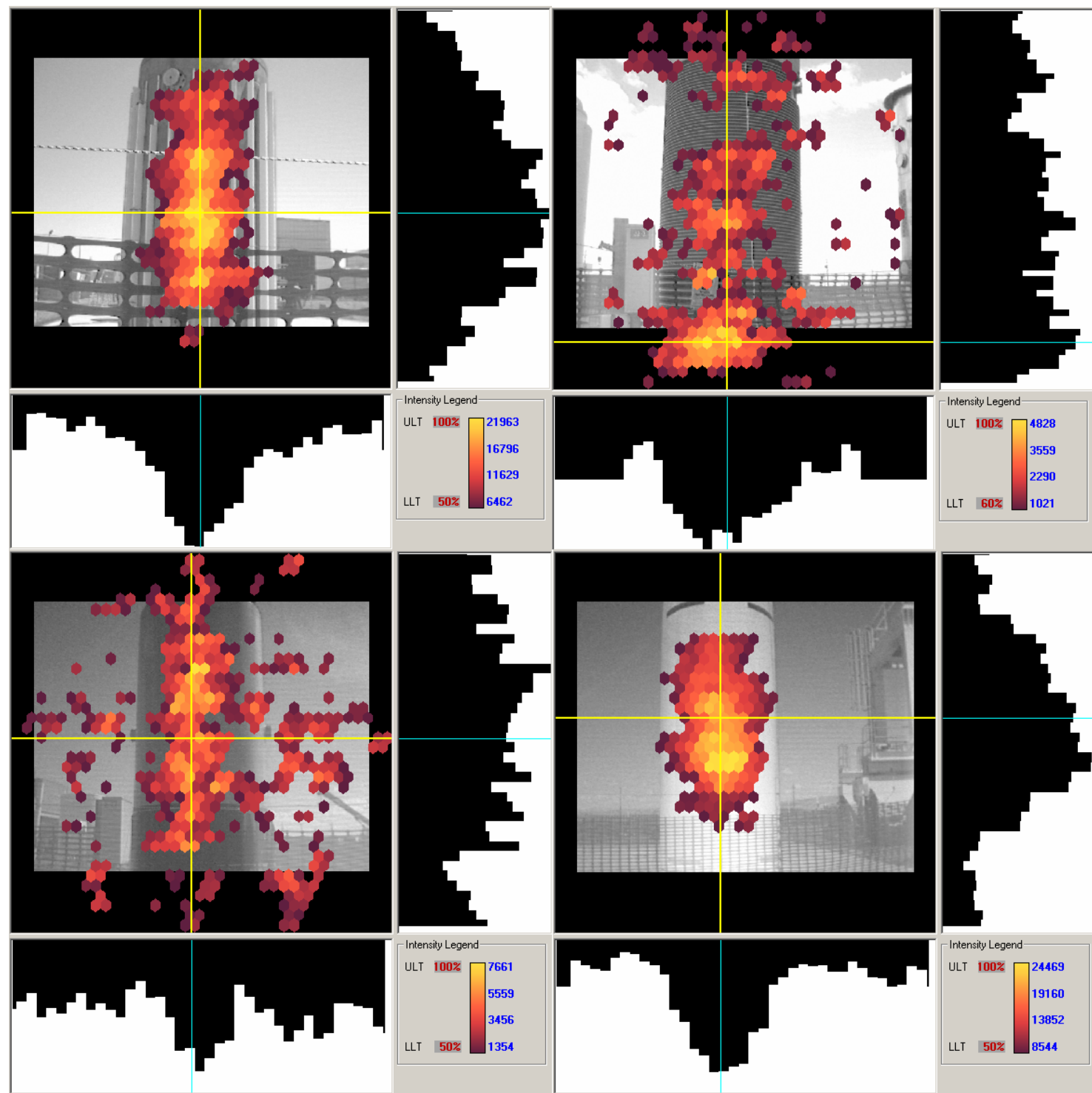

Fig. 38. Wide-field, gamma-ray images of casks (clockwise from top left) 1, 3, 4 and 5. The exposures are from similar distances and one hour in duration. The histograms on the right and bottom of the individual images are the counts under the vertical and horizontal cursor lines, respectively.

appropriate for a projection of the circular source distribution one would expect, while the side view shows the appropriate rectangular projection. Unfortunately, it is clear from the images obtained that insufficient detail exists to achieve the end-goal of individual cask identification.

To realize a successful fingerprint will require increasing the level of detail in the images. At a minimum, one will require the ability to image the individual fuel assemblies loaded around the periphery of the cask. Our results show that this means creating an image using primarily non-scattered radiation. Since gamma-rays lose energy when they scatter, any radiation detected in a nuclear emission line cannot have scattered on the way out of the cask and should carry the fingerprint information desired. The data from the Ge spectrometer, clearly shows that significant line emissions survive to the cask surface. If we look at the $662 \mathrm{keV}$ line from the various casks, we find that the ratio of unscattered to scattered radiation varies from $\sim 0.54: 1$ for cask 3 to 1.24:1 for cask 5. However, an examination of the spectrum for the best case shows that for a NaI-type energy resolution, this degrades by approximately a factor of 20 to $0.06: 1$. This degradation is primarily due to the large scattered component created in the lines and indicates that an instrument with good spectral resolution is required. 
Table 3

Summary of Spectroscopic Measurements

\begin{tabular}{|c|c|c|c|c|c|c|c|c|c|c|c|}
\hline \multirow[b]{2}{*}{ cask } & \multirow[b]{2}{*}{ type } & \multicolumn{3}{|c|}{ gamma-ray } & \multicolumn{4}{|c|}{ Counts } & \multicolumn{2}{|c|}{ Significance } & \multirow[b]{2}{*}{ remarks } \\
\hline & & nuclide & $\begin{array}{c}\text { energy, } \\
\text { keV }\end{array}$ & type & gross & net & sigma & bkg & Net/sigma & net/bkg & \\
\hline 1 & MC10 & B & 477 & capture & 105732 & 2297 & 543 & 103435 & 4.2 & 0.022 & \\
\hline & \multirow{10}{*}{$\begin{array}{l}1000 \text { live sec } \\
22.9 \% \text { dead }\end{array}$} & Cs-137 & 662 & fiss. prod. & 62420 & 30231 & 348 & 32189 & 86.9 & 0.939 & \\
\hline & & Co-60 & 1173 & fiss. prod. & 6864 & 1906 & 104 & 4958 & 18.3 & 0.384 & \\
\hline & & Co-60 & 1332 & fiss. prod. & 6840 & 4214 & 107 & 2626 & 39.4 & 1.605 & \\
\hline & & Eu-154 & 1274 & fiss. prod. & 16038 & 11070 & 168 & 4968 & 65.9 & 2.228 & \\
\hline & & Eu-154 & 1596 & fiss. prod. & 3355 & 2134 & 77 & 1221 & 27.7 & 1.748 & \\
\hline & & $\mathrm{Fe}$ & 1725 & capture & 1167 & 336 & 51 & 831 & 6.6 & 0.404 & \\
\hline & & $\mathrm{Si}$ & 1778 & $\left(\mathrm{n}, \mathrm{n}^{\prime}\right.$ gamma) & 751 & 216 & 31 & 535 & 7.0 & 0.404 & \\
\hline & & $\mathrm{Ca}$ & 1942 & capture & 489 & 47 & 20 & 442 & 2.4 & 0.106 & \\
\hline & & $\mathrm{H}$ & 2223 & capture & 2591 & 1947 & 64 & 644 & 30.4 & 3.023 & \\
\hline & & $\mathrm{Si}$ & 3536 & capture & 312 & 56 & 26 & 256 & 2.2 & 0.219 & \\
\hline \multirow[t]{11}{*}{2} & 125B2 & $\mathrm{B}$ & 477 & capture & 29452 & 298 & 156 & 29154 & 1.9 & 0.010 & \\
\hline & \multirow{10}{*}{$\begin{array}{c}1000 \text { live sec } \\
16.1 \% \text { dead }\end{array}$} & Cs-137 & 662 & fiss. prod. & 42340 & 22396 & 256 & 19944 & 87.5 & 1.123 & \\
\hline & & Co-60 & 1173 & fiss. prod. & 7871 & 1996 & 143 & 5875 & 14.0 & 0.340 & \\
\hline & & Co-60 & 1332 & fiss. prod. & 6921 & 4432 & 114 & 2489 & 38.9 & 1.781 & \\
\hline & & Eu-154 & 1274 & fiss. prod. & 13460 & 10061 & 136 & 3399 & 74.0 & 2.960 & \\
\hline & & Eu-154 & 1596 & fiss. prod. & 2977 & 1962 & 76 & 1015 & 25.8 & 1.933 & \\
\hline & & $\mathrm{Fe}$ & 1725 & capture & 540 & 107 & 27 & 433 & 4.0 & 0.247 & \\
\hline & & $\mathrm{Si}$ & 1778 & $\left(\mathrm{n}, \mathrm{n}^{\prime}\right.$ gamma $)$ & 569 & 172 & 29 & 397 & 5.9 & 0.433 & \\
\hline & & $\mathrm{Ca}$ & 1942 & capture & 535 & 62 & 35 & 473 & 1.8 & 0.131 & \\
\hline & & $\mathrm{H}$ & 2223 & capture & 1669 & 1129 & 54 & 540 & 20.9 & 2.091 & \\
\hline & & $\mathrm{Si}$ & 3536 & capture & 196 & 36 & 14 & 160 & 2.6 & 0.225 & \\
\hline
\end{tabular}




\begin{tabular}{|c|c|c|c|c|c|c|c|c|c|c|c|}
\hline \multirow[b]{2}{*}{ cask } & \multirow[b]{2}{*}{ type } & \multicolumn{3}{|c|}{ gamma-ray } & \multicolumn{4}{|c|}{ Counts } & \multicolumn{2}{|c|}{ Significance } & \multirow[b]{2}{*}{ remarks } \\
\hline & & nuclide & $\begin{array}{c}\text { energy, } \\
\mathrm{keV}\end{array}$ & type & gross & net & sigma & bkg & Net/sigma & net/bkg & \\
\hline 3 & $V / 21$ & $\mathrm{~B}$ & 477 & capture & 99121 & 5611 & 687 & 93510 & 8.2 & 0.060 & \\
\hline & \multirow{10}{*}{$\begin{array}{l}1000 \text { live sec } \\
21.2 \% \text { dead }\end{array}$} & Cs-137 & 662 & fiss. prod. & 52646 & 19112 & 369 & 33534 & 51.8 & 0.570 & \\
\hline & & Co-60 & 1173 & fiss. prod. & 7307 & 1691 & 132 & 5616 & 12.8 & 0.301 & \\
\hline & & Co-60 & 1332 & fiss. prod. & 6725 & 3820 & 122 & 2905 & 31.3 & 1.315 & \\
\hline & & Eu-154 & 1274 & fiss. prod. & 14452 & 10875 & 144 & 3577 & 75.5 & 3.040 & \\
\hline & & Eu-154 & 1596 & fiss. prod. & 2897 & 2039 & 64 & 858 & 31.9 & 2.376 & \\
\hline & & $\mathrm{Fe}$ & 1725 & capture & & & & & & & not observed \\
\hline & & $\mathrm{Si}$ & 1778 & $\left(\mathrm{n}, \mathrm{n}^{\prime}\right.$ gamma $)$ & 506 & 56 & 27 & 450 & 2.1 & 0.124 & \\
\hline & & $\mathrm{Ca}$ & 1942 & capture & & & & & & & not observed \\
\hline & & $\mathrm{H}$ & 2223 & capture & 1704 & 1275 & 51 & 429 & 25.0 & 2.972 & \\
\hline & & $\mathrm{Si}$ & 3536 & capture & & & & & & & not observed \\
\hline \multirow[t]{11}{*}{4} & REA-2023 & $\mathrm{B}$ & 477 & capture & 63015 & 1467 & 487 & 61548 & 3.0 & 0.024 & \\
\hline & \multirow{10}{*}{$\begin{array}{c}2,000 \text { live sec } \\
9.3 \% \text { dead }\end{array}$} & Cs-137 & 662 & fiss. prod. & 33575 & 14724 & 235 & 18851 & 62.7 & 0.781 & \\
\hline & & Co-60 & 1173 & fiss. prod. & 7215 & 1388 & 118 & 5827 & 11.8 & 0.238 & \\
\hline & & Co-60 & 1332 & fiss. prod. & 6482 & 3009 & 113 & 3473 & 26.6 & 0.866 & \\
\hline & & Eu-154 & 1274 & fiss. prod. & 22251 & 15607 & 208 & 6644 & 75.0 & 2.349 & \\
\hline & & Eu-154 & 1596 & fiss. prod. & 4927 & 3041 & 91 & 1886 & 33.4 & 1.612 & \\
\hline & & $\mathrm{Fe}$ & 1725 & capture & 1287 & 185 & 46 & 1102 & 4.0 & 0.168 & \\
\hline & & $\mathrm{Si}$ & 1778 & $\left(\mathrm{n}, \mathrm{n}^{\prime}\right.$ gamma $)$ & & & & & & & not observed \\
\hline & & $\mathrm{Ca}$ & 1942 & capture & & & & & & & not observed \\
\hline & & $\mathrm{H}$ & 2223 & capture & 12483 & 11522 & 124 & 961 & 92.9 & 11.990 & \\
\hline & & $\mathrm{Si}$ & 3536 & capture & & & & & & & not observed \\
\hline
\end{tabular}




\begin{tabular}{|c|c|c|c|c|c|c|c|c|c|c|c|}
\hline \multirow[b]{2}{*}{ cask } & \multirow[b]{2}{*}{ type } & \multicolumn{3}{|c|}{ gamma-ray } & \multicolumn{4}{|c|}{ Counts } & \multicolumn{2}{|c|}{ Significance } & \multirow[b]{2}{*}{ remarks } \\
\hline & & nuclide & $\begin{array}{c}\text { energy, } \\
\text { keV }\end{array}$ & type & gross & net & sigma & bkg & Net/sigma & net/bkg & \\
\hline \multirow[t]{11}{*}{5} & TN-24P & B & 477 & capture & 87396 & 5664 & 704 & 81732 & 8.0 & 0.069 & \\
\hline & \multirow{10}{*}{$\begin{array}{c}1000 \text { live sec } \\
18.7 \% \text { dead }\end{array}$} & Cs-137 & 662 & fiss. prod. & 45640 & 25308 & 287 & 20332 & 88.2 & 1.245 & \\
\hline & & Co-60 & 1173 & fiss. prod. & 6051 & 1712 & 118 & 4339 & 14.5 & 0.395 & \\
\hline & & Co-60 & 1332 & fiss. prod. & 5139 & 3410 & 94 & 1729 & 36.3 & 1.972 & \\
\hline & & Eu-154 & 1274 & fiss. prod. & 11153 & 8205 & 138 & 2948 & 59.5 & 2.783 & \\
\hline & & Eu-154 & 1596 & fiss. prod. & 2399 & 1414 & 76 & 985 & 18.6 & 1.436 & \\
\hline & & $\mathrm{Fe}$ & 1725 & capture & & & & & & & not observed \\
\hline & & $\mathrm{Si}$ & 1778 & $\left(\mathrm{n}, \mathrm{n}^{\prime}\right.$ gamma $)$ & 284 & 63 & 17 & 221 & 3.7 & 0.285 & \\
\hline & & $\mathrm{Ca}$ & 1942 & capture & 329 & 40 & 23 & 289 & 1.7 & 0.138 & \\
\hline & & $\mathrm{H}$ & 2223 & capture & 1173 & 889 & 41 & 284 & 21.7 & 3.130 & \\
\hline & & $\mathrm{Si}$ & 3536 & capture & 150 & 7 & 11 & 143 & 0.6 & 0.049 & \\
\hline \multirow[t]{11}{*}{6} & VSC-17 & B & 477 & capture & & & & 0 & & & not observed \\
\hline & \multirow{10}{*}{$\begin{array}{c}1000 \text { live sec, } \\
26.1 \% \text { dead }\end{array}$} & Cs-137 & 662 & fiss. prod. & 69212 & 35306 & 406 & 33906 & 87.0 & 1.041 & \\
\hline & & Co-60 & 1173 & fiss. prod. & 6025 & 1398 & 113 & 4627 & 12.4 & 0.302 & \\
\hline & & Co-60 & 1332 & fiss. prod. & 4455 & 2481 & 86 & 1974 & 28.8 & 1.257 & \\
\hline & & Eu-154 & 1274 & fiss. prod. & 15571 & 11935 & 157 & 3636 & 76.0 & 3.282 & \\
\hline & & Eu-154 & 1596 & fiss. prod. & 2956 & 2042 & 72 & 914 & 28.4 & 2.234 & \\
\hline & & $\mathrm{Fe}$ & 1725 & capture & 549 & 76 & 35 & 473 & 2.2 & 0.161 & \\
\hline & & $\mathrm{Si}$ & 1778 & (n, n' gamma) & 429 & 71 & 24 & 358 & 3.0 & 0.198 & \\
\hline & & $\mathrm{Ca}$ & 1942 & capture & 368 & 108 & 20 & 260 & 5.4 & 0.415 & \\
\hline & & $\mathrm{H}$ & 2223 & capture & 1024 & 695 & 38 & 329 & 18.3 & 2.112 & \\
\hline & & $\mathrm{Si}$ & 3536 & capture & 92 & 19 & 10 & 73 & 1.9 & 0.260 & \\
\hline
\end{tabular}




\section{Ideal Gamma-Ray Imager}

The results obtained during the measurement campaign provide some design parameters for a gamma-ray imager that should be able to obtain unique cask fingerprints. As discussed above, the spectral resolution will have to be high to obtain a useable signal to noise ratio. In addition, the flux in the line radiation indicates a detector surface area of $\sim 50 \mathrm{~cm}^{2}$ will provide reasonable images on hour timescales.

Ideally the field of view would encompass the entire cask with enough resolution to isolate individual fuel rod assemblies. With typical $2 \mathrm{~m} \times 5 \mathrm{~m}$ cask dimensions and a fuel assembly center-to-center spacing of $\sim$ $20 \mathrm{~cm}$, a minimum of $\sim 20,10-\mathrm{cm}$ pixels are required across the cask, with 2.5 times that number to see the full cask height. This gives a field of view with $\sim 50 \mathrm{x}$ 50 resolution elements. To properly oversample such a mask pattern requires a detector with $\sim 100 \times 100$ pixels. For an end-on-view, only half this number would be required in each dimension.

With the high fill factor of the gamma-ray emitting surfaces, the optimum signal-to-noise performance will occur with a coded aperture imager having less than a $50 \%$ open fraction.[4] In fact, for a system taking end views, a pin-hole camera may be able to obtain images in almost the same time as a coded aperture imager. It has a further advantage that concerns of seeing neighboring casks with a partially coded pattern are not present. This effect takes sources just outside the field of view and makes them appear on the opposite side of the image and increases systematic noise in the image. It can be removed with the simple design modification that incorporates collimation to restrict the field of view of every detector pixel to $1 / 4$ of the overall mask (a single mask pattern.) This will diminish the instruments sensitivity towards the edges of the field of view. The potential advantages of the pin-hole camera may be negated by the instrument weight since significant shielding will be required in the high-flux environment of a cask farm.

Because, the primary information content in the gamma-ray images comes from radiation at $662 \mathrm{keV}$ and above, Compton imagers may prove a suitable imager type for this application. In these instruments the direction of origin of individual gamma-rays is localized to a ring of possible directions with the final image comprised of overlapping rings. The increased information obtained about each gamma-ray (a narrow ring, rather than $1 / 2$ to $1 / 3$ the field of view, as in a coded-aperture imager) means that signal to noise is improved. A number of groups are actively working on this technology,[16-18] but it will still be at least five years before practical instruments can be available.
Even then, the cost of such units is likely to be high ( \$1M.)

\section{Neutron results}

The creation of a meaningful cask image using thermal neutrons depends on three factors. First, there must be sufficient residual neutron activity from spontaneous fission or $(\alpha, n)$ reactions in the spent fuel assemblies. Second, a fraction of these fast neutrons must be thermalized by scattering with hydrogen before reaching the surface of the cask. Third, the thermal neutrons must be able to escape into the air by diffusion to the surface without being absorbed.

The casks constructed with an external concrete shell are most suitable to meet these requirements, provided they contain a sufficient quantity of neutron-producing spent-fuel materials. The fast neutrons have a mean free path in concrete which varies with the hydrogen content, but there is likely to be a measurable flux of thermal neutrons leaking from the surface. The multiple scattering of neutrons in thick concrete walls makes it difficult to extract much information about the shape of the fuel loading because the images are dominated by thermal neutrons diffusing to the external surfaces. However, there are still noticeable differences in shapes of the images obtained from casks 1,2 and 5. These shapes provide a crude type of signature that is not easily predicted or faked.

Casks that are constructed predominantly of steel may be penetrated by significant fluxes of fast neutrons without much thermalization. Casks in which neutron absorbing layers like borated hydrocarbons are part of the design are unlikely to give a usable thermal neutron signature.

Just as with gamma-rays, there may be an unscattered component to the neutron flux. This would be carried by fast neutrons. In fact, the lack of an image of one of the steel casks was somewhat surprising at first, considering the neutron dose information taken by heath physicists at the site. The cask with the highest dose provided no thermal-neutron signature. Since the dose meters rely on a thermalizing sphere of polyethylene to moderate the fast neutrons, the lack of a thermalneutron image is a direct confirmation that fast neutrons are emitted by this cask. Thus, if a fast-neutron imager could be developed, it would probably be much more effective in characterizing the contents of the casks than thermal neutrons. A design for such an instrument is being developed by our BNL collaborators, and has shown promising results. 


\section{Conclusions}

The results of the measurement campaign did not directly validate the concept of fingerprinting dry storage casks. However, they do suggest that further measurements are warranted. The gamma-ray results indicate that a significant flux of unscattered radiation does escape the casks. Further, they show that the signal-tonoise ratio is high enough to generate images if an imager with suitable high-energy response and energy resolution is used. The thermal-neutron results are less promising. However, there is evidence that fissionspectrum neutrons do reach the cask surface. If imaged, these neutrons should also provide unique cask signatures.

\section{Recommendations}

To determine if radiation signatures can be used to uniquely identify dry storage casks, further work is required. An additional measurement campaign should be conducted with a germanium-based or comparable gamma-ray imager. The two primary requirements for the follow-on instrument are extended energy response to fission product gamma-ray lines and neutron capture peaks, and excellent energy resolution (comparable to a Ge spectrometer.) Pending results from these measurements, a design study of the optimum imager for the cask farm environment should be undertaken. Additional measurements with a fission spectrum neutron imager are also clearly indicated. As such instruments are currently under development, the potential applications to the IAEA should be made known to the sponsoring agencies. As early as practical, a further measurement campaign with such an instrument should be conducted.

It is clear that the radiation levels from the fuel assemblies are sufficient to generate images, even through the heavy shielding in the cask walls. If unshielded, it should be possible to obtain gamma-ray images, even from significant distances. As such, an additional use for the imaging technologies would be to monitor loading of the casks. Given the intense radiation fields, it is possible that one could even obtain images in the short exposure times required to make motion pictures. The value of tracking the individual radioactive elements throughout the loading process should be considered by the safeguards community.

\section{Acknowledgements}

This work was performed under the auspices of the U.S. Department of Energy by University of California, Lawrence Livermore National Laboratory under Contract W-7405-Eng-48.

\section{References}

1. "Forming images with thermal neutrons", P.E.Vanier, L. Forman, Proc. SPIE, 4784A, pp. 183-193, 2002.

2. A Large-Area PSPMT Based Gamma-ray Imager with Edge Reclamation, K.P. Ziock, L. Nakae,. IEEE Trans. Nucl. Sci., 49, 1552-1559, 2002.

3. Coded aperture imaging with uniformly redundant arrays, E.E. Fenimore, T.M. Cannon, Applied Optics, 17, no. 3, pp. 337-347, Feb., 1978.

4. Coded aperture imaging: predicted performance of uniformly redundant arrays, E.E. Fenimore, Applied Optics, 17, no. 22, pp. 3562-3570, Nov., 1978.

5. Coded aperture imaging in $X$ - and gamma-ray astronomy, E. Caroli, J.B. Stephen, G. Di Cocco, L. Natalucci, A. Spizzichino, Space Sci. Rev., 45, 394-403, 1987.

6. A Gamma-Ray Imager for Arms Control Verification, K.P. Ziock, T.B. Gosnell, C.J. Hailey, J.H. Lupton, F.A. Harrison, IEEE Trans. Nucl. Sci. 39, 1046 (1992).

7. W. R. Cook, M. Finger, T.A. Prince, E.C. Stone, IEEE Trans. Nucl. Sci., NS-31, 771 (1984).

8. New family of binary arrays for coded aperture imaging, S. Gottesman, E. Fenimore, Applied Optics, 28, no. 20, pp. 4344-4352, Oct. 1989.

9. Hamamatsu Photonics K.K., 314-5, Shimokanzo, Toyooka-village, Iwata-gun, Shizuoka-ken, 4380193, Japan

10. Real time generation of images with pixel-by-pixel spectra for a coded aperture imager with high spectral resolution, K.P. Ziock, M.T. Burks, W. Craig, L. Fabris, E.L. Hull, N.W. Madden, , NIM B, 505, 420-424, 2003.

11. Improvements in coded aperture thermal neutron imaging, Peter E. Vanier, Proc. SPIE, 5199-A, pp.124-131, 2003.

12. A.J. Caffrey, et al., IEEE Trans. Nuc. Sci. 39, pp. 1422-1426, 1992.

13. INEEL Spent Nuclear Fuel Integrated Transfer Schedule, available from:

http://www.id.doe.gov/DOEID/RFPSharedLibrary/ refdoc.htm as:

http://www.id.doe.gov/DOEID/RFPSharedLibrary/ PDF/PLN\%20845\%20Rev\%202\%20from\%20DO C.pdf 
14. R.E. Einziger, H.C. Tsai, M. C. Billone, , B.A. Hamilton, Proc. of ICONE10, $10^{\text {th }}$ Int. Conf. on Nucl. Eng., Arlington, VA, April 14-18, 2002.

15. Transactions, SMiRT 16 paper \#1309, Washington DC, Aug. 2001.

16. Thick silicon strip detector Compton imager, E.A. Wulf, B.F. Phlips, W.N. Johnson, J.D. Kurfess, E.I. Novikova, IEEE Trans. Nuc. Sci., 51, pp.19972003, 2004.
17. 4 pi Compton imaging using a 3-D positionsensitive CdZnTe detector via weighted list-mode maximum likelihood., C.E. Lehner, Zhong He, Feng Zhang. IEEE Trans. Nuc. Sci., 51, pp.16181624, 2004.

18. Gamma-ray imaging with position-sensitive HPGe detectors, K. Vetter, M. Burks, L Mihailescu, NIM A , 525, pp.322-32, 2004. 